Prepared for the U.S. Department of Energy

under Contract DE-AC05-76RL01830

\title{
Assessment of Jet Erosion for Potential Post-Retrieval K-Basin Settled Sludge
}

\author{
BE Wells \\ CW Enderlin \\ PA Gauglitz \\ RA Peterson
}

September 2009

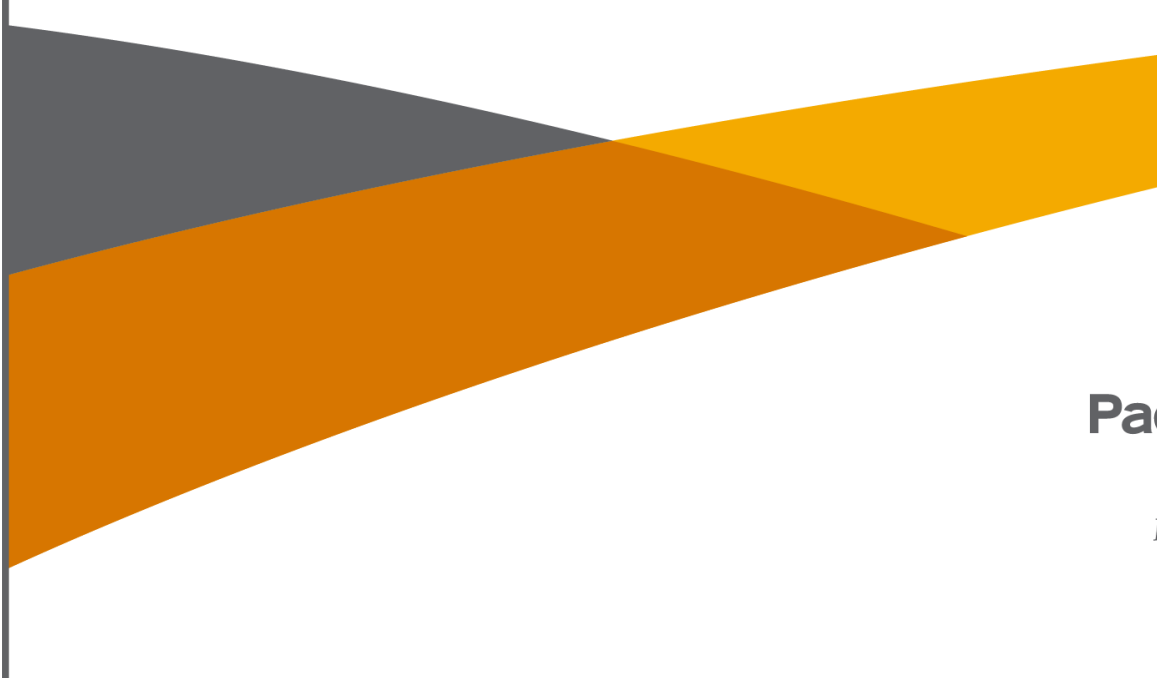




\title{
DISCLAIMER
}

This report was prepared as an account of work sponsored by an agency of the United States Government. Neither the United States Government nor any agency thereof, nor Battelle Memorial Institute, nor any of their employees, makes any warranty, express or implied, or assumes any legal liability or responsibility for the accuracy, completeness, or usefulness of any information, apparatus, product, or process disclosed, or represents that its use would not infringe privately owned rights. Reference herein to any specific commercial product, process, or service by trade name, trademark, manufacturer, or otherwise does not necessarily constitute or imply its endorsement, recommendation, or favoring by the United States Government or any agency thereof, or Battelle Memorial Institute. The views and opinions of authors expressed herein do not necessarily state or reflect those of the United States Government or any agency thereof.

\author{
PACIFIC NORTHWEST NATIONAL LABORATORY \\ operated by \\ BATTELLE \\ for the \\ UNITED STATES DEPARTMENT OF ENERGY \\ under Contract DE-ACO5-76RL01830
}

Printed in the United States of America
Available to DOE and DOE contractors from the Office of Scientific and Technical Information,
P.O. Box 62, Oak Ridge, TN 37831-0062;
ph: (865) 576-8401
fax: (865) 5765728
email: reports@adonis.osti.gov

\footnotetext{
Available to the public from the National Technical Information Service, U.S. Department of Commerce, 5285 Port Royal Rd., Springfield, VA 22161 ph: (800) 553-6847 fax: (703) 605-6900

email: orders@ nits.fedworld.gov online ordering: http://www.ntis.gov/ordering.htm
} 


\title{
Assessment of Jet Erosion for Potential Post-Retrieval K-Basin Settled Sludge
}

\author{
BE Wells \\ CW Enderlin \\ PA Gauglitz \\ RA Peterson
}

September 2009

Prepared for

the U.S. Department of Energy

under Contract DE-AC05-76RL01830

Pacific Northwest National Laboratory

Richland, Washington 



\section{Summary}

Packaged K-Basin sludge will be transported to the T Plant on the Hanford Site where it will be interim stored. The sludge will be retrieved from the storage containers and processed for disposal. A sample of high uranium content canister sludge, designated 96-13, "self-cemented" during laboratory storage. This sample was uncharacteristically strong compared to expected K-Basin material. The purpose for this work is to evaluate the potential retrieval of such sludge after storage at the T Plant via jet erosion.

The specific objectives of this report are to determine the modes of erosion and the methods used to measure/assess the erodibility parameters of sludge and identify those parameters applicable to jet erosion. The erodibility parameters of sample 96-13 are characterized to the extent possible. These objectives have been met based on literature review, past experience at Pacific Northwest National Laboratory, and observation of sample 96-13 video during hot-cell activities.

Sample 96-13 is characterized as a heterogeneous cohesive sediment with "paste" material (estimated shear strength 3 to $5 \mathrm{kPa}$ ) joining "chunks" (estimated shear strength 380 to $770 \mathrm{kPa}$ ). The bulk material shear strength is estimated at 15 to $65 \mathrm{kPa}$, which is within the range of shear strengths for cohesive sludges used for erosion investigations. These shear strength estimates are taken from visual observation of the 96-13 sample settling study disassembly video and are based on estimated applied forces, approximated contact areas, and the application of an estimate of the relation of compressive and shear stresses and must therefore be treated as qualitative. The estimated shear-strength results are qualitatively in agreement with the measured shear strength for hydrothermally treated K-Basin samples. General recommendations for measuring the shear strength of materials such as sample 96-13 are provided.

A summary of erosion phenomena for and application to both impinging and parallel wall jets for cohesive and non-cohesive materials is presented. For cohesive materials, the material yield stress in shear (shear strength) provides an upper bound for the applied shear stress from the jet necessary to initiate material erosion. The critical shear stress provides a material-dependent lower bound for the applied shear stress required to initiate erosion. The erosion rate is a function of the applied stress. Recommendations for the determination of the critical shear stress for the onset bulk erosion for application with hot-cell samples are summarized. Additional characterization/assessment of potential non-cohesiveness material in K-Basin sludge is recommended to confirm that a material layer with an erosive resistance greater than the capacity of the erosion source is not created. 



\section{Acronyms and Abbreviations}

$\begin{array}{ll}\text { CHPRC } & \text { CH2M Hill Plateau Remediation Company } \\ \text { CSM } & \text { cohesive strength meter } \\ \text { DOE } & \text { U.S. Department of Energy } \\ \text { D/T } & \text { impeller diameter to vessel diameter ratio } \\ \text { KE } & \text { K East } \\ \text { KW } & \text { K West } \\ \text { PCB } & \text { polychlorinated biphenyl } \\ \text { RH-TRU } & \text { remote-handled transuranic waste } \\ \text { SD } & \text { strongly deflected (jet regime) } \\ \text { TSCA } & \text { Toxic Substances Control Act } \\ \text { UCS } & \text { unconfined compressive strength } \\ \text { UDS } & \text { undissolved solids } \\ \text { WD } & \text { weakly deflected (jet regime) }\end{array}$





\section{Contents}

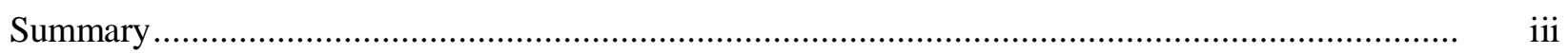

Acronyms and Abbreviations............................................................................................

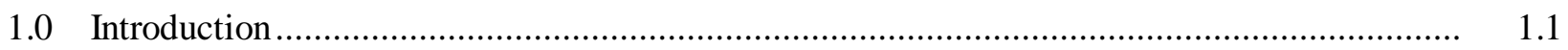

2.0 Jet Erosion Mechanisms …………....................................................................... 2.1

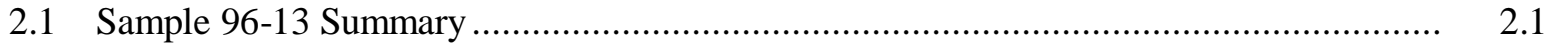

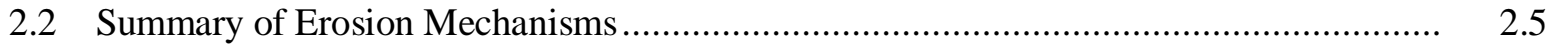

2.2.1 Modes of Particulate Erosion ........................................................................... 2.6

2.2.2 Material Parameters .............................................................................. 2.16

2.2.3 Operational Conditions ................................................................................ 2.17

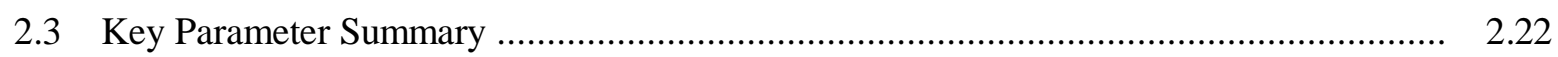

3.0 Parameter Measurement............................................................................................. 3.1

3.1 Shear Strength Measurements ................................................................................... 3.1

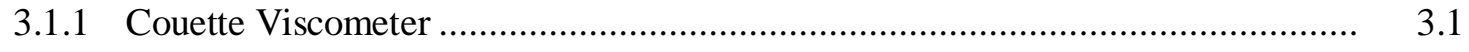

3.1.2 Shear Vane .................................................................................... 3.2

3.1.3 Waste Core Extrusion Behavior …………………….................................. 3.2

3.1.4 Soil Penetrometer .................................................................................. 3.3

3.2 Critical Shear Strength for Erosion ........................................................................... 3.3

3.2.1 Proposed Method for Obtaining Critical Shear Stress in Hot Cell ....................... 3.5

4.0 Sample 96-13 Assessment.................................................................................... 4.1

4.1 Sample 96-13 Shear Strength Estimates …………................................................... 4.1

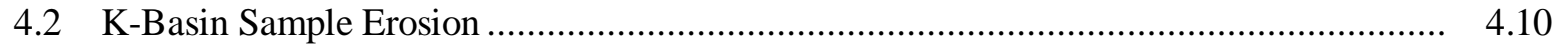

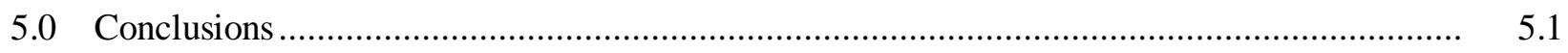

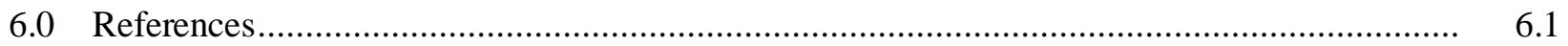




\section{Figures}

2.1. Sample $96-13$ in the Graduated Cylinder (3.8 cm outer diameter).

2.2. Sample 96-13 Fracture Plane and Side View After Removal from the Graduated Cylinder (3.8 cm outer diameter).

2.3. Sample 96-13 Close-up After Removal from the Graduated Cylinder................................. 2.4

2.4. Sample 96-13 Piece with 0.25-Inch Hex-Wrench............................................................ 2.4

2.5. Depiction of Entrainment in Bed of Homogenous Material ............................................... 2.7

2.6. Depiction of Floc Erosion in Bed of Homogenous Material .............................................. 2.8

2.7. Depiction of Surface Erosion from a Bed of Homogenous Material ................................... 2.9

2.8. Depiction of Mass Erosion from a Bed of Homogenous Material ........................................ 2..13

2.9. Graphical Qualitative Representation of the Erosion Rate as a Function of Applied Stress for a Single Material.

2.10. Diagram of Scour Hole Produced by Impinging Jet with Characteristic Length Scales Identified

2.11. Diagram of Scour Hole Produced by Wall Jet with Characteristic Length Scales Identified

3.1. Schematic of a Conceptual Test Apparatus for Hot-Cell Erosion Assessment

4.1. Sample 96-13 Shear Strength Estimate 1. Top View in Graduated Cylinder.

4.2. Sample 96-13 Shear Strength Estimate 1. Spoon blade is at lower right; "imprint" of spoon blade tip appears to be visible at center.

4.3. Sample 96-13 Shear Strength Estimate 2. Start of forceps impingement.

4.4. Sample 96-13 Shear Strength Estimate 2. Impingement of forceps tip evident.............

4.5. Sample 96-13 Shear Strength Estimate 3. Start of forceps impingement.

4.6. Sample 96-13 Shear Strength Estimate 3. Impingement of forceps tip

4.7. Sample 96-13 Shear Strength Estimate 4. Chunk prior to contact with hex wrench.

4.8. Sample 96-13 Shear Strength Estimate 4. Hex wrench in contact with chunk for impingement.

4.9. Sample 96-13 Shear Strength Estimate 4. Chunk expelled to lower left, "chip" is left in original location.

4.10. Sample 96-13 Shear Strength Estimate 5. Hex wrench placement.

4.11. Sample 96-13 Shear Strength Estimate 5. After fracture.

4.12. Sample 96-13 Shear Strength Estimate 6. Initial sample condition prior to hex wrench placement.

4.13. Sample 96-13 Shear Strength Estimate 6. Post hex wrench interaction. 


\section{Tables}

4.1. 96-13 Sample Shear Strength Estimate Identification............................................... 4.2

4.2. 96-13 Sample Shear Strength Estimates ................................................................... 4.10

4.3. Processed K-Basin Sludge Erosion (Delegard et al. 2007) ............................................. 4.11

4.4. Processed K-Basin Sludge Erosion Applied Shear Comparison............................................ 4.13 



\subsection{Introduction}

Irradiated metallic uranium fuel from the N Reactor on the Hanford Site was stored in two waterfilled concrete pools, 105-K East Basin (KE-Basin) and 105-K West Basin (KW-Basin), at the U.S. Department of Energy's (DOE's) Hanford Site. Radioactive sludges from the storage and corrosion of this fuel are present in the K-Basins. The sludge is a mix of fuel corrosion products (including metallic uranium and metal oxidation products), iron and aluminum hydroxides/oxides, concrete grit, sand, infiltrated soil, and operational and biological debris (Delegard et al. 2007).

One of the primary DOE objectives for the CH2M Hill Plateau Remediation Company (CHPRC) contract is to complete the removal of all $\mathrm{K}$-Basin sludge remaining in the KW-Basin, thereby enabling demolition of the facilities and safe storage of the KW reactor building itself. Completion of this work will in turn enable CHPRC to complete the remediation of soil and groundwater contamination to protect the Columbia River and complete the remediation of the last waste sites in the River Corridor.

To complete this task, CHPRC must remove and package the sludge that is or will be located in the six large engineered containers (SCS-CON- 210, -220, -230, -240, -250, and -260) in the K West (KW) Basin. Upon exiting the K-Basins, the packaged sludge will be transported to T Plant on the Hanford Site where it will be managed as remote-handled transuranic waste (RH-TRU) and regulated as a polychlorinated biphenyl (PCB) remediation waste under the Toxic Substances Control Act (TSCA). After interim storage in T Plant, the sludge will be retrieved from the storage containers and processed for $\operatorname{disposal.~}^{(\mathrm{a})}$

K-Basin sludge samples have been collected, characterized, and evaluated since 1995 to support sludge management. The compaction and dryout properties of K East (KE)-Basin sludge samples during long-term storage were characterized by Delegard et al. (2005). One canister sludge sample with high uranium content, designated 96-13, "self-cemented" and could not be re-suspended into supernatant liquid at the end of the 28-month settling test period. The retrieval of such sludge after interim storage in T Plant via jet erosion is addressed in this report. The objectives of this report are to:

- Determine the modes of erosion and the methods used to measure/assess the erodibility parameters of sludge.

- Identify those parameters applicable to jet erosion.

- Characterize erodibility parameters of sample 96-13.

A summary of jet erosion, emphasizing those phenomena pertinent to sample $96-13$, is provided in Section 2 along with a summary of the literature for jet erosion mechanics for cohesive and non-cohesive materials. The parameters for characterizing the erosion sediment are described. Measurement techniques based on literature review and past experience at Pacific Northwest National Laboratory for specific sediment parameters are discussed in Section 3, again with regard to the characteristics of sample 96-13. In Section 4, characterization of sample 96-13 is provided based on visual observation of a 96-13

(a) Letter, CJ Osso, DOE Richland Operations, to JG Lehew III, CHPRC, “Contract No. DE-AC06-08RL 14788 External Technical Review (ETR) of the Hanford K Basins Sludge Treatment Project (STP),” 09-AMRC-0173, 0901904A, dated August 19, 2009. 
sample video. An evaluation of jet erosion in hydrothermally treated K-Basin materials with similar characteristics to that of 96-13 is conducted. Conclusions are provided in Section 5. 


\subsection{Jet Erosion Mechanisms}

To provide a basis for the discussion of jet erosion, the general characteristics of sample 96-13 are summarized in Section 2.1. Jet erosion mechanisms are summarized in Section 2.2, and the key sediment parameters for erosion are listed in Section 2.3.

\subsection{Sample 96-13 Summary}

Sludge sample 96-13 was a KE-Basin canister sludge sample that had evaporated to dryness before the long-term storage investigation of six K-Basin sludges presented in Delegard et al. (2005). The 96-13 sample was crushed and re-wetted for the long-term storage characterization.

As reported in Delegard et al. (2005), the 96-13 sample had a high uranium concentration relative to the other five sludge samples considered. No correlation was identified in the drying (water loss) tests between the water loss rates and the composition/radioactivity of the six samples. With the exception of one sample with an observed high gas-generation rate, the settled-sludge density changed little from 7 days to 28 months. The settled sludge density was observed to increase with uranium concentration in the sludge solids.

The effect of vibration on sludge compaction was tested 112 days into the settling test (Delegard et al. 2005). The vibration testing was conducted by agitating the samples in a laboratory vortex mixer. The mixer was described to provide high oscillatory frequency "...vigorous swirling action, but with little vertical vibration." Sample 96-13 did not have "good mixing" “...even with mixer setting of 5" ("5" is the maximum vortex mixer speed setting applied to 96-13) while mixing was observed in the other samples (maximum vortex mixer speed setting of 3.5).

At the end of the 28-month settling test period, the settled sludge samples were returned to storage jars. With the exception of 96-13, the sludge materials were re-suspended readily and could be transferred to storage jars by repeated slurrying and decanting steps. The 96-13 sample had "selfcemented" and could not be re-suspended into supernatant liquid, even when the cylinder was inverted and shaken. Delegard et al. (2005) reported that the self-agglomeration of 96-13, although more pronounced, was similar to the physical form of KE-Basin sludge plus fuel-piece samples investigated by Schmidt et al. (2003). No other K-Basin sample has been observed to self-cement at hot cell conditions, provided that the samples are kept immersed in water.

The 96-13 sample settling study disassembly video has been visually observed, and the "self cemented" sediment is characterized on this visual observation as a heterogeneous cohesive sediment with "paste" material joining "chunks." The paste material is "soft" relative to the chunks. Figure 2.1 shows the sample in the graduated cylinder, and Figure 2.2 shows a fracture plane and side view of the sample after the graduated cylinder was broken and the sample removed. A close-up view of the sample is provided in Figure 2.3. The paste is silver in color, while the chunks are black and may be up to $1.3 \mathrm{~cm}$ in length. ${ }^{(a)}$ There are no visually observable differences in the composition of the undisturbed sample

(a) Each graduation on the cylinder is approximately $0.21 \mathrm{~cm}(0.08 \mathrm{inch})$. 
that was at the vessel wall to the material that was exposed when the sample was broken. A piece of the sample with paste surrounding chunks is shown in Figure 2.4; the hex-wrench is 0.25 inch.

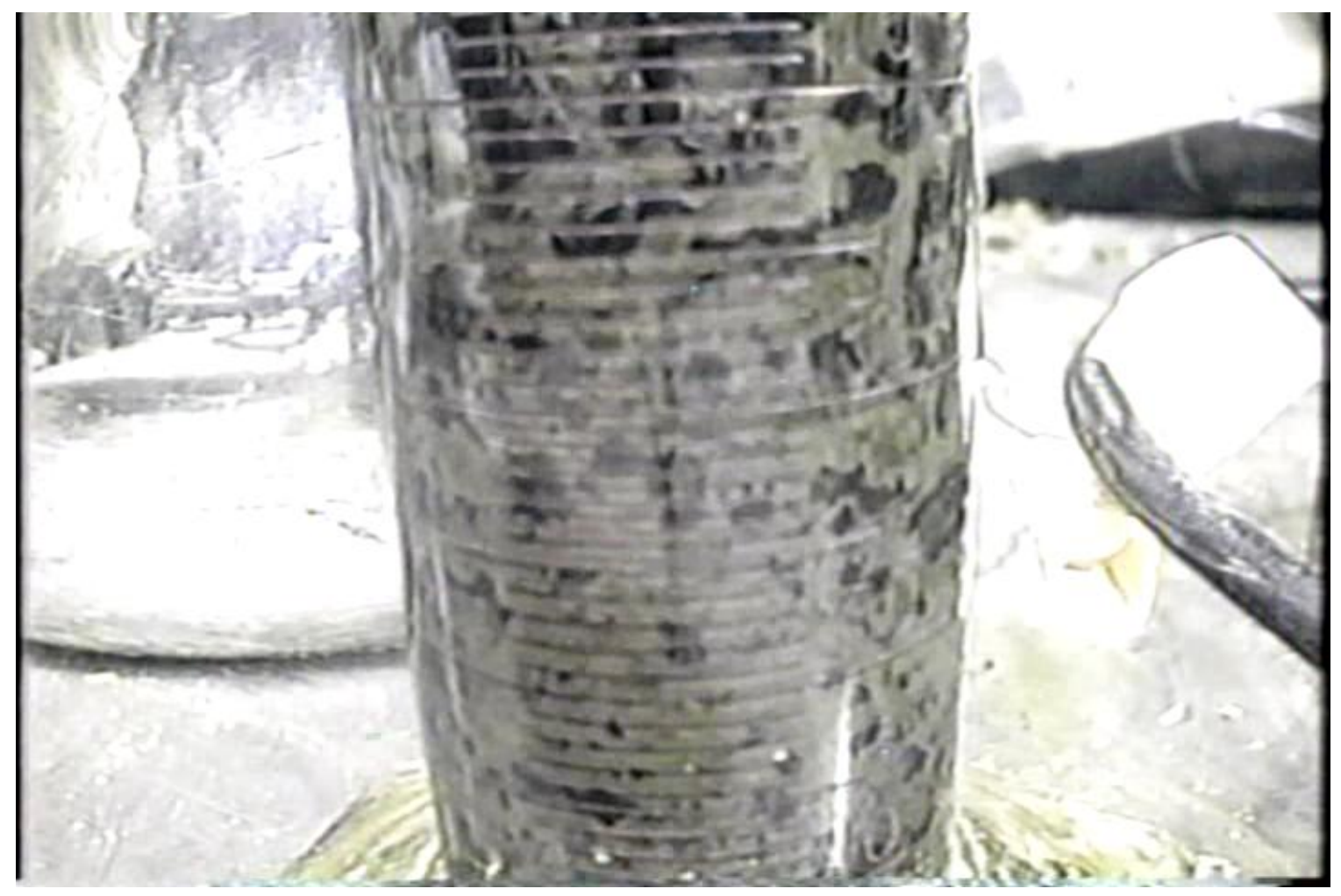

Figure 2.1. Sample $96-13$ in the Graduated Cylinder ( $3.8 \mathrm{~cm}$ outer diameter) 


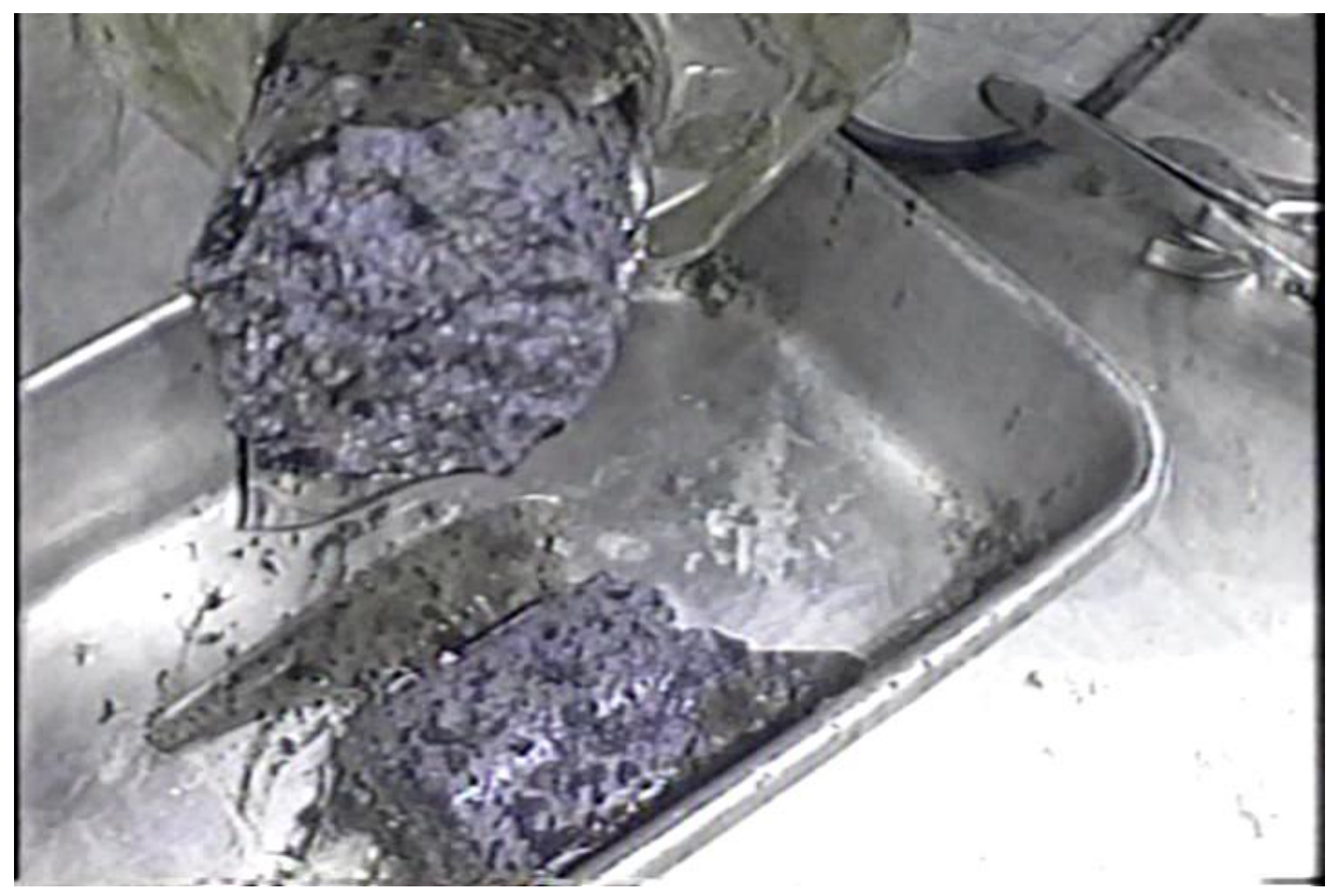

Figure 2.2. Sample 96-13 Fracture Plane and Side View After Removal from the Graduated Cylinder (3.8 cm outer diameter) 


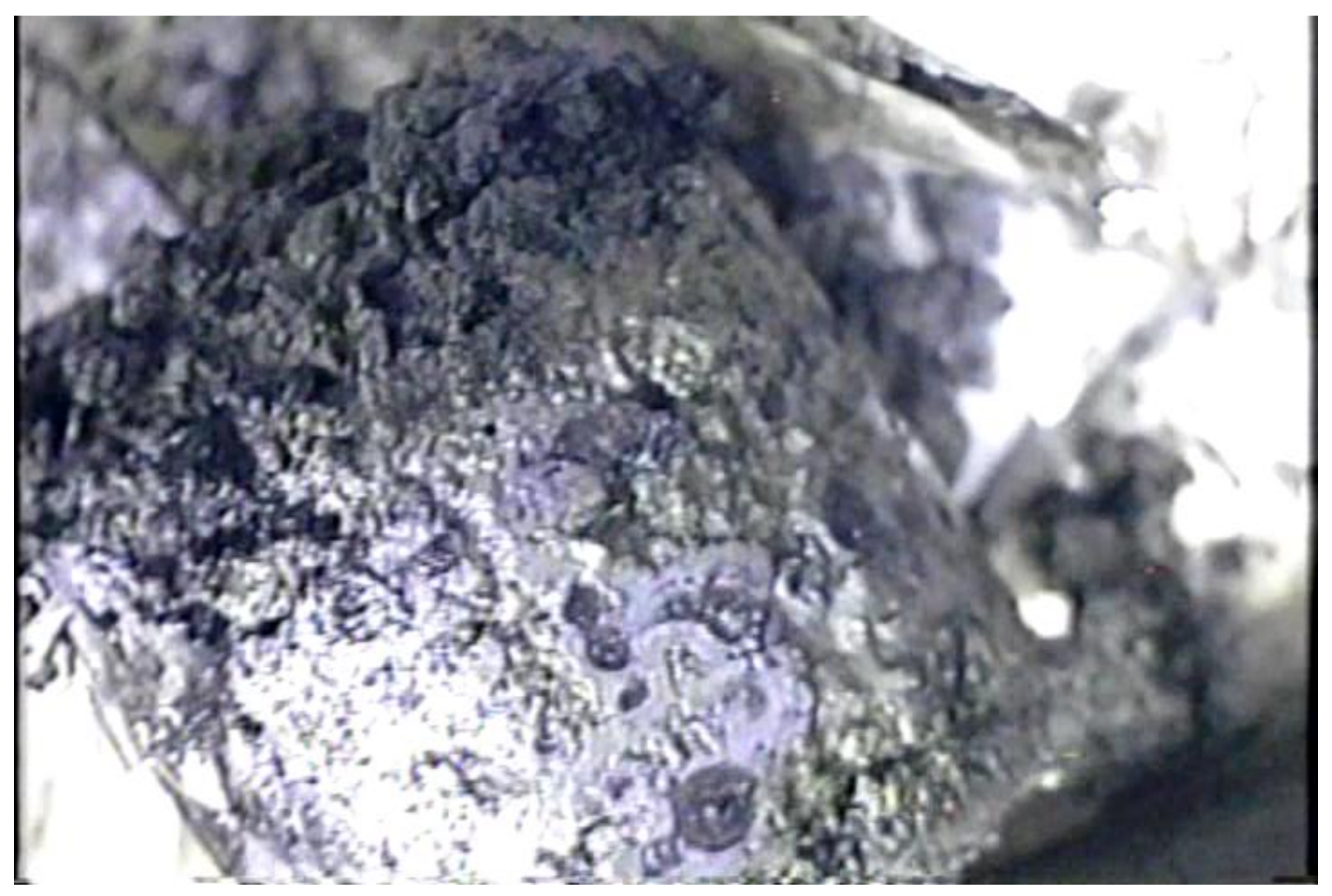

Figure 2.3. Sample 96-13 Close-up After Removal from the Graduated Cylinder. Upper left is fracture plane, center is side "as-formed" view, inner-diameter of graduated cylinder is $3.5 \mathrm{~cm}$.

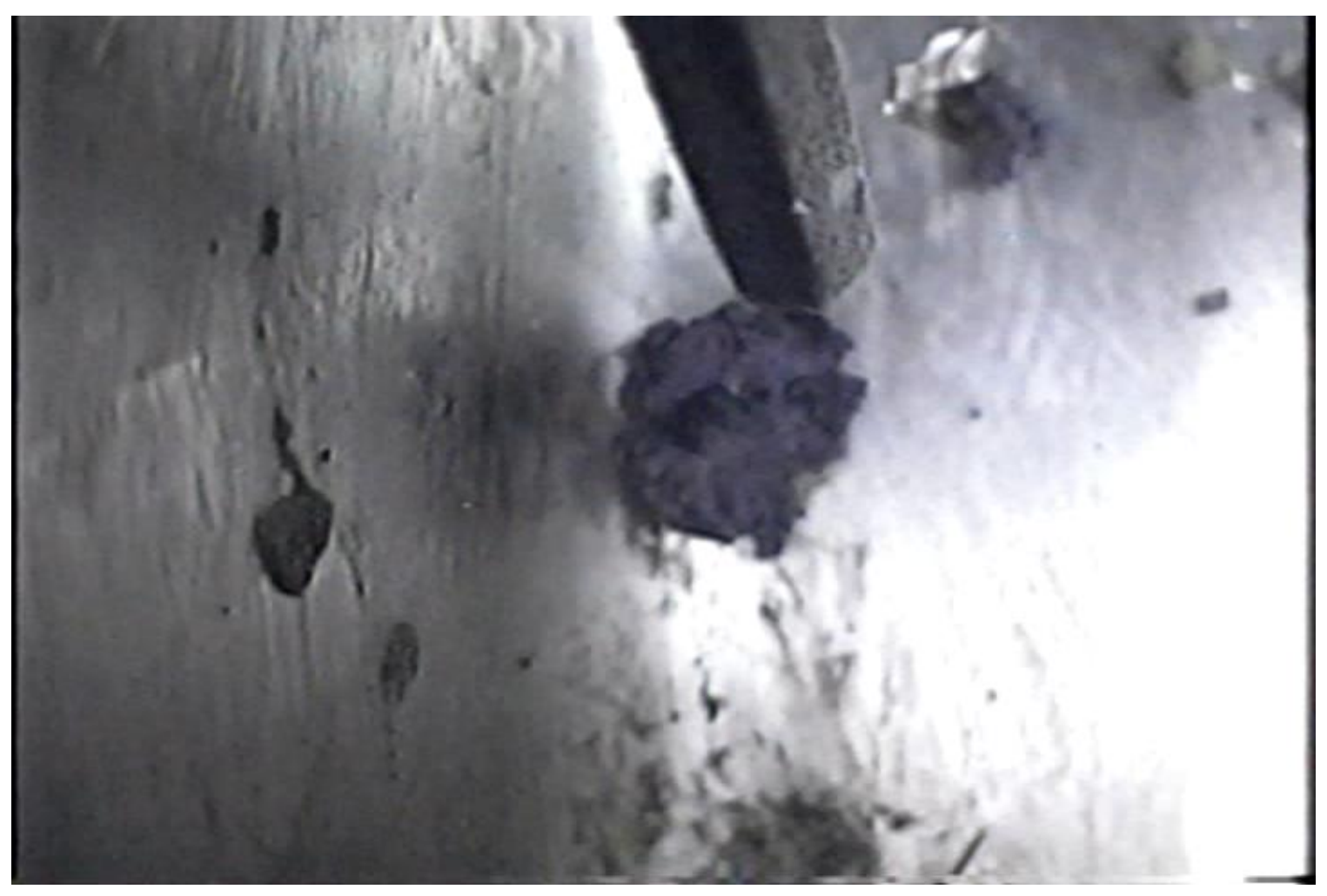

Figure 2.4. Sample 96-13 Piece with 0.25-Inch Hex-Wrench 


\subsection{Summary of Erosion Mechanisms}

Erosion is the removal of material by physical means from a surface or body. For the purpose of this report, the mechanisms of erosion for particulate material, compacted slurries (sediments), and pastes will be discussed as opposed to non-particulate materials such as metals, ceramics, plastics, etc. Particulate material can be separated into two categories: non-cohesive and cohesive materials.

Non-cohesive, or cohesionless, materials typically consist of large-diameter particles (>75 $\mu \mathrm{m})$ where mechanical interaction (e.g., packing, interlocking, size variation) provides the majority of the material bed strength, and particle size and density govern the erosion process. The weight of the particle scales with the diameter cubed (volume) and the drag/lift forces scale with the diameter squared (crosssectional area). The submerged weight (difference between weight and buoyancy) of the particles is a dominant force to be overcome for erosion to occur. Non-cohesive particles react to forces imposed by fluid, and the movement of the particles is dominated by the particulate characteristics, such as size, shape, density, and packing.

Particles less than $75 \mu \mathrm{m}$ but greater than $2 \mu \mathrm{m}$ may behave as non-cohesive material; however, particles in this size range are subject to colloidal forces (inter particle attractive and repulsive forces) that can depend on the $\mathrm{pH}$ and ionic content of the interstitial liquid and material constituents. Materials in this size range tend to exhibit some degree of cohesive behavior.

Cohesive materials consist of particle sizes less than $75 \mu \mathrm{m}$. The resistance of cohesive material to erosion depends on the strength of the cohesive forces binding the particles. Cohesion may far outweigh the influence of the physical characteristics of the individual particles. In most cases, the submerged weight of the individual particles in a cohesive bed is so small it is considered negligible. Once erosion takes place, cohesive material may become non-cohesive with respect to transport. For particle sizes less than $2 \mu \mathrm{m}$, forces contributing to the cohesiveness include van der Waals forces, Coulombic attraction, electrical double layer forces, and hydration forces.

Within the literature, the breakup or disassociation of particulate materials is discussed in terms of material failure, mobilization, and erosion. Material failure is the initiation of relative movement of the particulate such as deformation, fracture, shearing, and initial particle/material separation (removal). Simplified examples are the creation of a footprint or the insertion of a tool.

Mobilization is the rearranging of the spatial order of the bulk material beyond that of the initial failure. Bulk volumes of the material change their location with respect to other bulk regions of the material. A simplified example is plowing or spading. Bulk regions of material change position relative to one another, but no material is removed. Erosion is the combination of both material failure and removal of the material. For erosion to exist, the following must occur: material detachment, entrainment, and transport. Material detachment can be in the form of individual particles, flocs, or larger masses (e.g., "chunks", “clumps"). Refer to Section 2.2.1.

For the purpose of this report, the terms mobilization and erosion will be considered interchangeable, and no distinction will be made as to whether the material can be transported away after mobilization. Material failure tends to be the process most readily quantified for assessing the erosion/mobilization potential of materials (e.g. shear vane, penetrometer, and particle movement). Section 2.2.1 presents the various modes of erosion that can occur for particulate materials. Section 2.2.2 identifies the parameters 
that influence the erosion process, and Section 2.2.3 discusses operational factors that influence the erosion of a particulate bed via a jet.

\subsubsection{Modes of Particulate Erosion}

The bulk of the literature and past work associated with particulate erosion due to liquid flow has been associated with the erosion of soils due to estuary and channel flows, which is dominated by flow parallel to the material surface. Additional work has been conducted for jet erosion with the dominant flow parallel to the material surface as in the configuration of the waste tank jet mixer pumps and for flow perpendicular to the material surface as in impinging jets used for sluicing operations. The bulk of the work reviewed for impinging jets addresses assessing the erodibility of different materials using an impinging jet. Sections 2.2.1.1 through Section 2.2.1.7 summarize the various modes of erosion and discuss the applicability of the different modes to cohesive and non-cohesive materials. Since the focus of this report is Sample 96-13, the emphasis of the discussion will be directed toward cohesive materials. The applicability of the different modes to jet flow will also be discussed. The descriptions of the various modes provided in the following sections assume a homogenous solids material (solids bed) and a dilute liquid (minimal entrained solids) as well as a two-dimensional flow field.

Sections 2.2.1.1 through 2.2.1.4 summarize the four modes of cohesive erosion; entrainment, floc erosion, surface erosion, and mass erosion; as categorized by Winterwerp and Van Kesteren (2004). The characterization of these modes is not unique within the literature. For some authors, floc erosion is included as surface erosion. However, the summary presented follows that outlined by Winterwerp and Van Kesteren. These four modes of erosion are not sequential and depend on the material bed properties, such as strength and permeability. Additional modes of erosion are summarized in Sections 2.2.1.5 through 2.2.1.7.

\subsubsection{Entrainment}

Entrainment (also referred to as fluidization) occurs when the material strength is weak ( $\tau_{\mathrm{S}}$ is negligible or approaches zero) and the particle size small such that the material bed behaves as a viscous fluid under the applied stresses. All material beds will not exhibit entrainment behavior. The eroding fluid can have the effect of

- inducing flow in the upper region of the bed material causing a mixing of the bed material and the overlying fluid that results in a rapid dilution of the solids material

- penetrating into the pores of the bed, thereby relieving the loads of the skeletal forces and eliminating the bed structure.

Erosion of the top surface of such material readily occurs when turbulent flow is applied via the overlying liquid for even a short duration, such as wave action or intermittent jet flow. The top surface of the bed is readily entrained and mixes with the turbulent liquid. The bulk mixing of the solids with the liquid occurs faster than the transport of the solids by the fluid. If turbulent flow is induced in the bed material, as in the case of an avalanche, the moving solids layer can entrain the overlying liquid layer.

For materials that are readily entrained, the surface of the solids layer does not provide a true physical boundary from which material is eroded as single particles (refer to Section 2.2.1.3) or clumps of material (refer to Section 2.2.1.4). Instead the flow penetrates or is induced in the upper region of the bed 
material. The material is readily disassociated into individual particles, for a depth, $h$, greater than the particle diameter, $d_{s}$, such that $h \gg d_{s}$ almost instantaneously. The bed surface behaves as an interface between two liquids.

The phenomenon is possible with non-cohesive solids if the applied stress is large enough and the submerged weight of the solids small. This would be for solids smaller than approximately $75 \mu \mathrm{m}$. However, for most conditions where entrainment occurs, the particle size is relatively small, resulting in the material exhibiting some form of weak cohesive behavior.

Entrainment occurs if the bed behaves as a viscous fluid (i.e., the resistive forces are small compared to those resulting from the applied stress), and the applied stress at the interface between the liquid and the solids layer significantly exceeds the bed (sediment) yield stress in shear, $\tau_{\mathrm{s}}$, if any, of the solids bed. Figure 2.5 is a schematic depicting entrainment for a homogenous material bed.

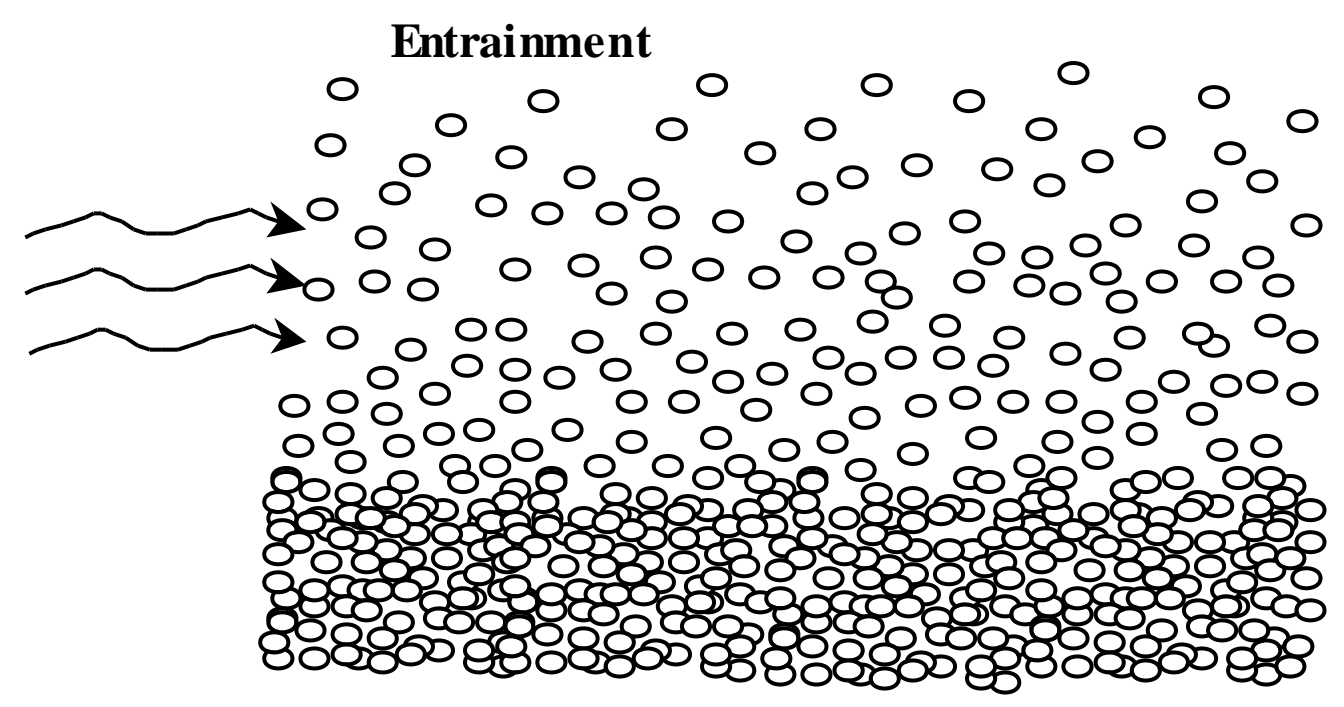

Figure 2.5. Depiction of Entrainment in Bed of Homogenous Material

\subsubsection{Floc Erosion}

Floc erosion is the removal of individual flocs of material from the bed surface as a result of the shear applied via the overlying fluid where a floc is a clump or aggregate of weakly bound particles created through aggregation of suspended particles. The flocs are removed when the flow-induced shear stresses on the bed exceed the strength of the adhesion of the flocs to the bed. Floc strength and adhesion strength may decrease in time because of cyclical application of the applied shear stress resulting from turbulent flow. Floc erosion is influenced by

- The number of flocs exposed to the flow

- The relative alignment/packing of the flocs within the bed

- The strength of floc adhesion to the bed

- The nature and magnitude of the applied shear stress to the bed surface. 
Flocs are not considered to exist in homogenous non-cohesive beds of particulate. A schematic depicting floc erosion is provided in Figure 2.6.

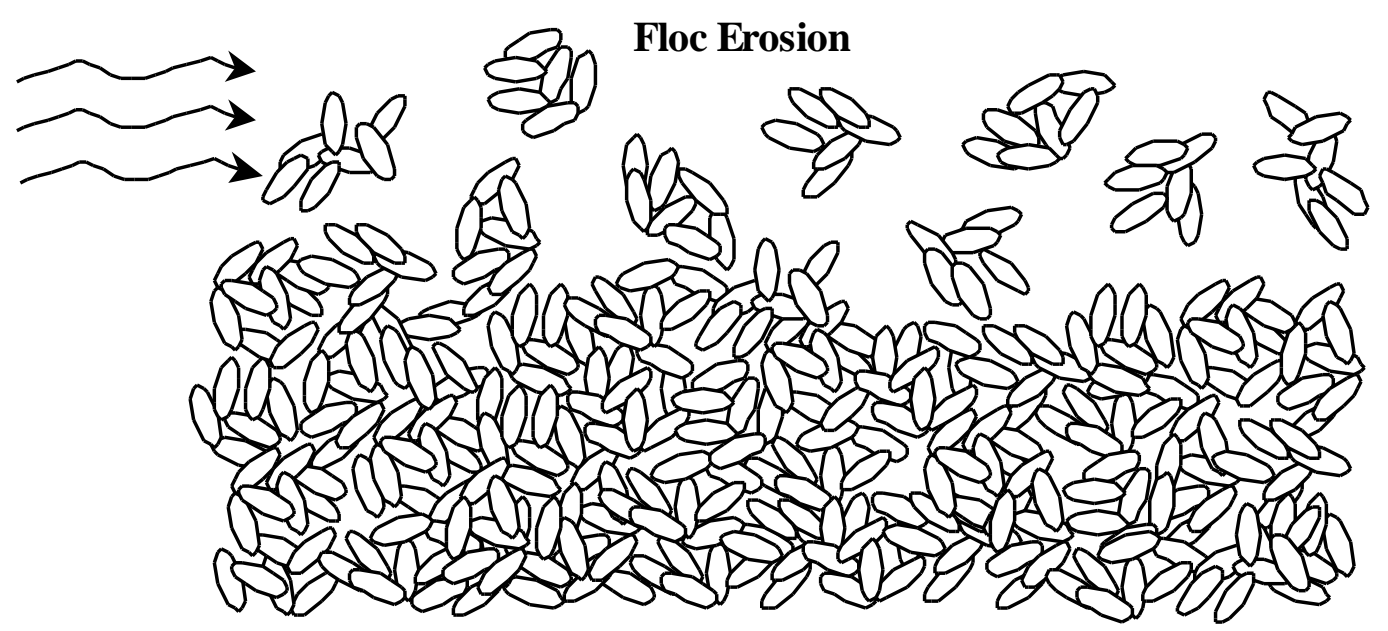

Figure 2.6. Depiction of Floc Erosion in Bed of Homogenous Material

\subsubsection{Surface Erosion}

Surface erosion is the basic mode of erosion most often considered and occurs when individual particles are removed from the bed surface. Figure 2.7 is a schematic representation of surface erosion from a bed of homogenous material. Surface erosion occurs when the shear stress applied by the fluid to the surface is at or above the bed's critical shear stress for erosion, $\tau_{c}$, . The critical shear stress for erosion is ideally the applied shear stress above which particulate will be removed from the bed surface. Because this parameter tends to be obtained from experimental measurements, it has been defined as

- The applied shear stress at which a defined minimum erosion rate is obtained

- Or the shear rate obtained when experimental measurements for various applied shear rates are extrapolated to a zero erosion rate or condition.

The determination of $\tau_{\mathrm{c}}$ has been varied and somewhat subjective. Refer to Section 3.2 for various methods used to obtain $\tau_{\mathrm{c}}$.

For surface erosion, the rate of particulate removal can be faster than the rate at which the removed particulate mixes with the overlying fluid. The removal of a particle from the surface is accompanied by the replacement of an equal volume of liquid, which creates a resulting flow of liquid into and out of the pores at the surface of the bed. The flow induced at the bed surface by the removal of a particle can have the effect of increasing the bed porosity at the surface. In instances where the bed porosity at the surface is affected, the bed swells as a result of hydrodynamic pressure fluctuation increasing the bed porosity, which reduces the shear strength at the bed surface. 


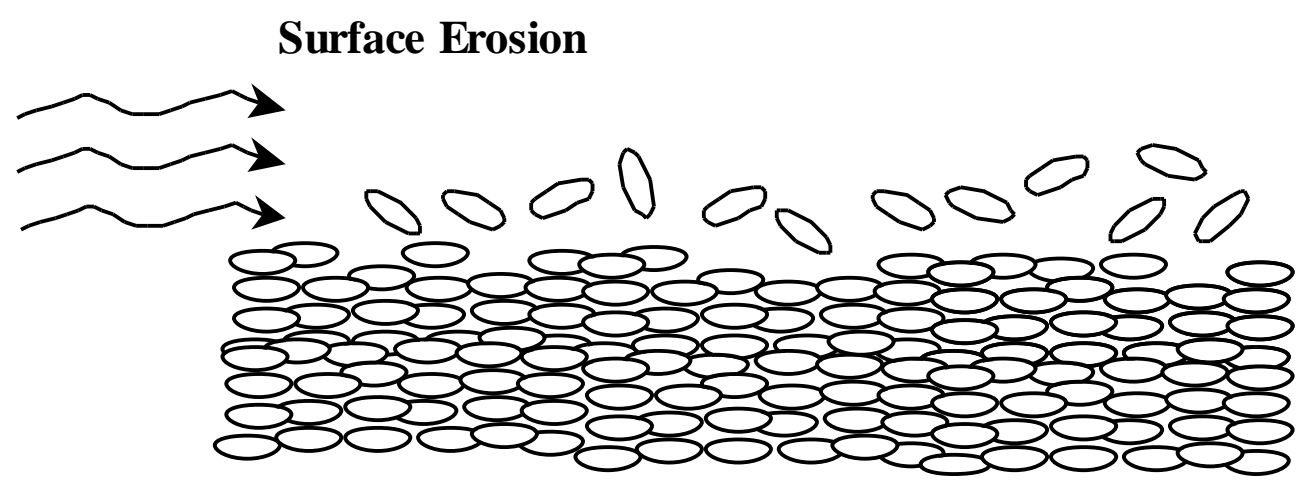

Figure 2.7. Depiction of Surface Erosion from a Bed of Homogenous Material

For non-cohesive materials, the forces acting upon an individual particle are the particle weight, $\mathrm{F}_{\mathrm{W}}$, and buoyancy, $F_{B}$, and the viscous drag force, $F_{D}$, resulting from the fluid flow past the particle. There actually exists both a drag and a lift force on the particle. For this simplified summary, $F_{D}$ is assumed to be the resultant force due to the effects of lift and drag. Assuming a spherical particle with a diameter $d_{p}$, and density $\rho_{\mathrm{s}}$ in a liquid with density $\rho_{\mathrm{l}}$, then

$$
\begin{gathered}
\mathrm{F}_{\mathrm{W}}=\frac{\pi d_{p}^{3} \rho_{s} g}{6} \\
\mathrm{~F}_{\mathrm{B}}=\frac{\pi d_{p}^{3} \rho_{l} g}{6} \\
\mathrm{~F}_{\mathrm{D}}=\frac{C_{D} A_{p} \rho_{l} U^{2}}{2}
\end{gathered}
$$

where $\mathrm{g}=$ gravitational acceleration

$\mathrm{C}_{\mathrm{D}}=$ drag coefficient for the particle

$\mathrm{U}=$ fluid velocity surrounding the particle

$\mathrm{A}_{\mathrm{p}}=$ area of projection of the particle perpendicular to the flow.

For a sphere, $A_{p}=\frac{\pi d_{p}^{2}}{4}$. The difference between $\mathrm{F}_{\mathrm{W}}$ and $\mathrm{F}_{\mathrm{B}}$ is referred to as the submerged weight, $\mathrm{W}_{\mathrm{S}}$.

Therefore, a simplified conclusion is that for non-cohesive material, erosion is expected to occur when $F_{D}>W_{s}$. Actually, the vertical component of $\mathrm{F}_{\mathrm{D}}$ must exceed that of $\mathrm{W}_{\mathrm{s}}$ for the particle to be lifted from the surface. A particle resting on the surface can initiate motion if the drag force is sufficient to overcome the frictional force of the particle on the bed surface, which is dependent on $\mathrm{W}_{\mathrm{s}}$. Additional factors that influence whether the applied shear stress can remove the particle from the bed is the packing or interlocking of the particle relative to the adjacent particles. A more detailed analysis of the particle would take into account the moments created by the drag and lift forces about a pinning point representing the particle's contact with a downstream stationary particle. 
Regardless of the detail of the analysis, the governing parameters are $\rho_{\mathrm{l}}, \rho_{\mathrm{s}}, \mathrm{U}, \mathrm{g}, \mathrm{d}_{\mathrm{p}}$ and $\mu$ where $\mu$ is the dynamic viscosity of the liquid. Through dimensional analysis of the parameter set, the following relationship can be obtained.

$$
\frac{\rho_{l} U^{2}}{g\left(\rho_{s}-\rho_{l}\right) d_{p}}=f\left\lfloor\frac{d_{p} \rho_{l} U}{\mu}\right\rfloor
$$

The left-hand side of Equation 2.4 represents a form of Froude number, the square root of which is referred to as the densimetric Froude number and is the ratio of the applied shear stress to gravitational force per unit volume. The right-hand side is a particle Reynolds number, which approximates the ratio of the particle diameter and the thickness of the viscous sub-layer. The dimensional analyses found in the literature take slightly different forms and will often include additional geometric parameters related to the geometry of interest, often associated with free surface flows.

Substitution can be used to modify the form of Equation 2.4. Assuming turbulent flow and the conditions necessary for the magnitude of the velocity to result in the critical shear stress, $\tau_{\mathrm{c}}$, being applied, then $\tau_{c} \approx \rho_{l} U_{c}^{2}$ where $\mathrm{U}_{\mathrm{c}}$ is the fluid velocity corresponding to $\tau_{\mathrm{c}}$ being applied. Kinematic viscosity, $v$, can be substituted for the quantity $\mu / \rho_{1}$ and the specific weight, $\gamma$, for the quantity g $\rho$ where the subscripts 1 and s represent liquid and solid, respectively. Equation 2.4 can then be rewritten as

$$
\frac{\tau_{c}}{\left(\gamma_{s}-\gamma_{l}\right) d_{p}}=f\left\lfloor\frac{d_{p} U_{c}}{v}\right\rfloor
$$

for the condition corresponding to the critical shear stress being applied. This is the form of the relationship used to define the Shields diagram (Simons and Senturk 1992), which is readily found within the literature associated with the mobilization of non-cohesive materials. The term on the left side of Equation 2.5 is often referred to as the Shields Parameter. Because $\tau_{c} \approx \rho_{l} U_{c}^{2}$, the right hand side of Equation 2.5 is often presented as $\frac{d_{p} \sqrt{\frac{\tau_{c}}{\rho_{l}}}}{v}$. Shields generated a graphical representation of the onset of particle motion (Shields Diagram) by measuring the bed-load transport for various values of $\tau /\left(\gamma_{s}-\gamma_{1}\right) d_{p}$ at least twice as large as the critical value and then extrapolated to the point of vanishing bed load. This indirect procedure was used to avoid the implications associated with the random orientation of particles and variations in localized flows in conditions close (both greater than and less than) to $\tau_{\mathrm{c}}$ (Simons and Senturk 1992).

The use of the Shields diagram to predict the onset of particle motion has its difficulties since the dependent parameters $\tau_{\mathrm{c}}$ and $\mathrm{d}_{\mathrm{p}}$ appear in both the ordinate and abscissa parameters for the diagram, thus preventing a simple and direct relationship between the two properties. This has led to attempts to define additional parameters and diagrams defining the onset of particle motion for non-cohesive particulate. Descriptions of the various methods are beyond the scope of this work, but suggested works include the "Task committee on Preparation of Sedimentation Manual (1966), Simons and Sentürk (1992), Gessler (1971, p. 22), and Julien (1995). 
The bulk of the work done to investigate the initiation of particle motion has used nearly uniform size particulate of one constituent. For the application of Shields' work to non-cohesive materials with nonuniform particulate and multiple constituents, a representative particle size and density must be determined for the bed material.

For Cohesive materials, the chemistry (e.g., $\mathrm{pH}$, ionic strength, organic matter) of the particulate and liquid influence the bed structure. The relative orientation of the particles can be classified as "edge to face," "face to face," or "edge to edge" (van Olhen 1977) and can significantly impact the strength of the bed structure. While cohesive materials exhibit a critical shear stress such that $\tau_{c}<\tau_{s}$, efforts to develop a comprehensive tool for predicting $\tau_{\mathrm{c}}$ have been limited. The consensus of past studies is that $\tau_{\mathrm{c}}$ increases with increases in $\tau_{\mathrm{s}}$, compressive strength, and plasticity index and $\tau_{\mathrm{c}}$ decreases with increases in porosity and moisture content. No consistency has been observed in correlating these parameters to predict $\tau_{\mathrm{c}}$. The difficulty associated with obtaining consistent correlations is partially contributed to the various types of materials used to conduct investigations and the different definition for $\tau_{\mathrm{c}}$. Refer to Section 3.2. Examples of predictive correlations for $\tau_{\mathrm{c}}$ include:

- Relating the critical shear stress to the bulk density of the bed. An increase in bed density generally increases the number of bonds between the particles, thus leading to higher shear strength. The following relation developed by Mitcheenr et al. is presented by Winterwerp and Van Kesteren (2004). Parameters are in SI units.

$$
\tau_{c}=0.015\left(\rho_{b}-1000\right)^{0.73}
$$

- Relating the critical shear stress to the plasticity index, $\mathrm{I}_{\mathrm{P}}$. The relationship developed by Smerdon and Beasley is presented by Winterwerp and Van Kesteren (2004). $\mathrm{I}_{\mathrm{P}}$ is in percent. It is worth noting that the following relationship was developed based on experiments with clay having remolded shear strengths ranging from $0.1 \mathrm{kPa}$ to $10 \mathrm{kPa}$. The critical shear stress is in units of $\mathrm{Pa}$.

$$
\tau_{c}=0.163 I_{P}^{0.84}
$$

- Relating the critical shear stress to both $\tau_{\mathrm{S}}$ and $\mathrm{I}_{\mathrm{p}}$. The relationship developed by Dunn is presented by Garde and Raju (2000). The relationship was developed from tests with materials having geometric mean sizes ranging from $14 \mu \mathrm{m}$ to $319 \mu \mathrm{m}$. The term in square brackets is in degrees, $\tau_{\mathrm{S}}$ is in $\mathrm{kPa}$, and $\tau_{\mathrm{c}}$ in $\mathrm{Pa}$.

$$
\tau_{c}=\left(\tau_{S}+8612\right) \operatorname{TAN}\left[30+1.73 I_{P}\right]
$$

YongHui et al (2008) and Garde and Ranga Raju (2000) provide an overview of correlations developed for $\tau_{\mathrm{c}}$ as a function of various cohesive material properties.

Surface erosion is expected to occur whenever $\tau>\tau_{\mathrm{c}}$. After determining that erosion will occur, the next item of interest is often the erosion rate. Substantial work has been done to predict the erosion rate of cohesive materials. Mehta (1991, pp. 40-53) provides a summary of erosion relationships developed by previous investigators. Mehta (1991, pp. 40-53) developed the following simple equation to describe the erosion rate that appears throughout the literature. 


$$
E=M\left(\frac{\tau-\tau_{c}}{\tau_{c}}\right)
$$

where $\mathrm{M}$ is an experimentally determined constant referred to as the erosion rate parameter. Both the erosion rate and the erosion rate parameter may be expressed in units of mass/(time $\bullet$ area). In other instances, the terms are divided by the density of the solid material being eroded, which yields $\mathrm{E}$ and $\mathrm{M}$ in terms of length/time. The difference between $\tau$ and $\tau_{\mathrm{c}}$ is referred to as the excess shear stress, which in Equation 2.9 is normalized by $\tau_{c}$. This equation has been applied to both non-cohesive and cohesive materials. Other forms of the equation include:

$$
E=M\left(\tau-\tau_{c}\right)^{a}
$$

and

$$
E=M\left(\tau-\tau_{c}\right)
$$

where $\mathrm{a}$ is an exponent often set equal to one and $\mathrm{M}$ is in units of time/length or (time $\bullet$ area)/mass for $\mathrm{E}$ expressed in terms of mass/(time•area) or length/time, respectively.

The difficulty in applying Equation 2.9 is the ambiguity associated with the definition of $\tau_{\mathrm{c}}$ or the subjectiveness in experimentally determining $\tau_{c}$. Difficulty also exists for non-cohesive materials in attempting to select representative values for $d_{p}$ and $\rho_{s}$ for determining $\tau_{c}$ from the Shields' diagram. Another issue is that $\mathrm{M}$ is sensitive to small errors in $\tau_{\mathrm{c}}$. Despite the difficulties associated with applying Equation 2.9, past investigations demonstrate that the rate of erosion for surface erosion tends to be linear with respect to the excess shear rate (i.e., double the excess shear stress, and the erosion rate can be expected to double). This linear increase in erosion rate is only applicable while surface erosion is the mode of erosion. A continual increase in the excess shear stress will eventually result in the onset of the phenomenon known as mass erosion. Refer to Section 2.2.1.4 for a description of mass erosion. While surface erosion can continue to occur in the presence of mass erosion, the resulting erosion rate will always be greater than that of surface erosion alone.

\subsubsection{Mass Erosion}

Mass erosion is independent of particle action at the surface of the bed. It occurs when the shear stress applied to the surface of the bed creates failure along a plane below the bed surface. This phenomenon occurs when the applied shear stress exceeds a minimal macroscopic yield stress along a plane of the bed (refer to follow on discussion) and results in large chunks of material being removed from the bed. These chunks of material are intact as they leave the bed and are not the result of rapid localized surface erosion. The depths of the removed chunks are significantly greater than the depth of any gradient in porosity resulting from surface erosion effects. A depiction of mass erosion is provided in Figure 2.8. 


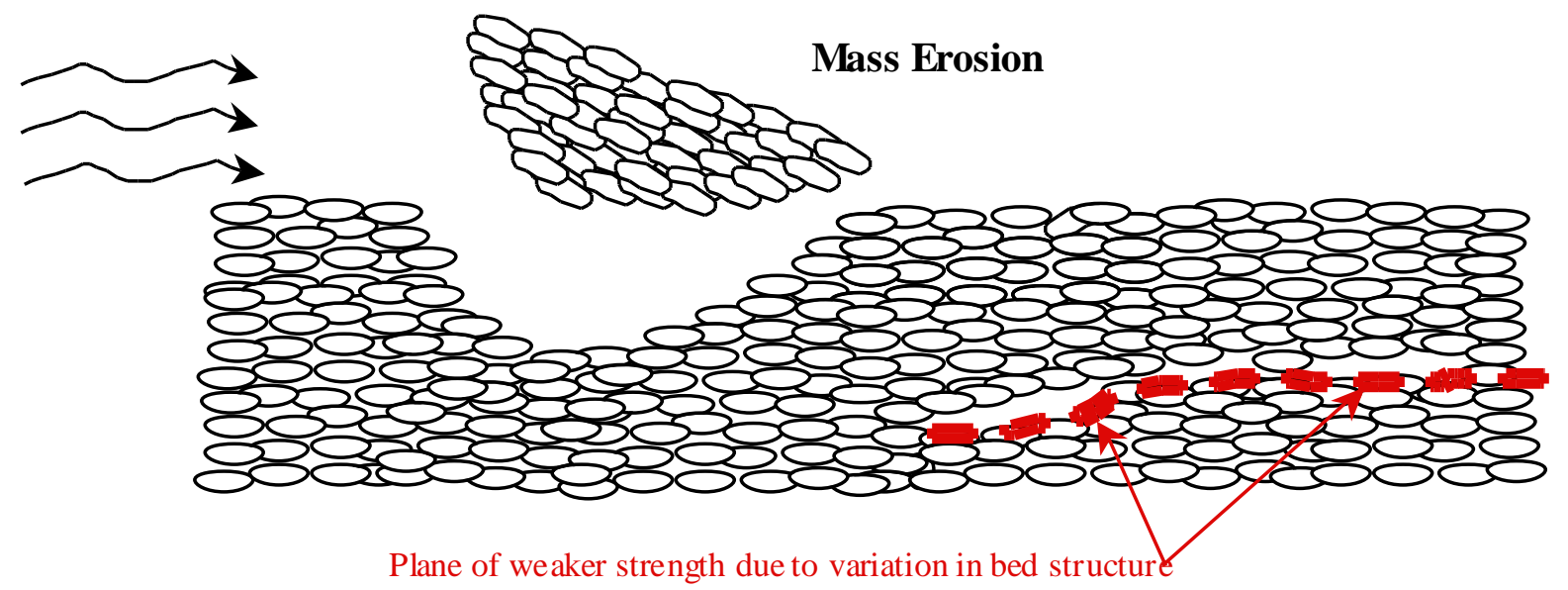

Figure 2.8. Depiction of Mass Erosion from a Bed of Homogenous Material

For flow parallel to the bed surface, a turbulent boundary layer can be assumed flowing across a solid surface. In an ideal homogeneous material with a flat surface, the applied shear stress required to cause mass erosion is expected to be the yield stress of the material in shear, $\tau_{\mathrm{s}}$. In this case, the dominating force applied by the flow at a location $\mathrm{x}$ on the surface will be the frictional force on the material surface resulting from the applied shear stress, which can be expressed as

$$
\tau_{f}=C_{f}\left(\frac{\rho_{l} U_{x}^{2}}{2}\right)
$$

where $\rho_{\mathrm{l}}$ is the liquid density, $\mathrm{U}_{\mathrm{x}}$ is the fluid velocity at location $\mathrm{x}$ on the bed surface, and $\mathrm{C}_{\mathrm{f}}$ is a wall frictional coefficient. For both laminar and turbulent flow boundary layers, wall-friction coefficients typically depend on the viscous Reynolds, $\operatorname{Re}_{\mathrm{v}}$, number such that

$$
C_{f}=C_{R}\left(\operatorname{Re}_{v}\right)^{-1 / b} \quad(\text { Bamberger et al. 2005) }
$$

where $C_{R}$ and $b$ are experimentally determined constants with $b$ often being in the range of 4 to 5 for many turbulent boundary layers (Bamberger et al. 2005) and

$$
\operatorname{Re}_{v}=\frac{\rho_{l} U_{x} \delta}{\mu_{l}}
$$

where $\delta$ is the local length scale for the boundary thickness or length along the boundary, and $\mu_{1}$ is the liquid viscosity.

Experimental results however, have demonstrated that this type of failure occurs at applied shear stresses, $\tau$, less than the measured $\tau_{\mathrm{S}}$ of the material. Failure by mass erosion will occur when the applied shear stress exceeds the strength of the weakest planes. Experimentally, this is often observed at applied shear stresses less than those measured for the material by laboratory instruments, such as a shear vane or 
penetrometer. Factors such as non-homogeneity, voids, and increased porosity can create localized weak spots within the material bed. These weaker locations create planes with a lower $\tau_{\mathrm{S}}$ than that of the bulk material. Laboratory measurements of shear stress are often made using a set geometry such as a cylinder for the shear plane as opposed to an arbitrarily weak plane. In the case of mass erosion, the applied shear stress is capable of generating failure at the weakest point in the material.

Another factor that contributes to mass erosion is the topography of the bed surface. A roughened surface allows a stagnation pressure to be created upstream of raised portions of the bed (e.g., mounds), resulting in an additional form drag on localized regions of the bed surface. This additional form drag results in the localized shear stress being greater than that predicted for the fluid flow over a flat surface. If a weak spot exists where mass erosion can be initiated, the initiation of mass erosion can be compounding as the bed surface becomes more irregular.

The erosion rate observed during bulk (mass) erosion will always be greater than the rate observed for surface erosion of the same material bed. Figure 2.9 provides a graphical qualitative representation of the erosion rate as a function of applied stress for a single material. The plot is labeled with the regions of stable bed, surface erosion, mass erosion, and complete failure. Some investigators have defined two critical shear stresses, one for the onset of surface erosion and another for the onset of mass erosion.

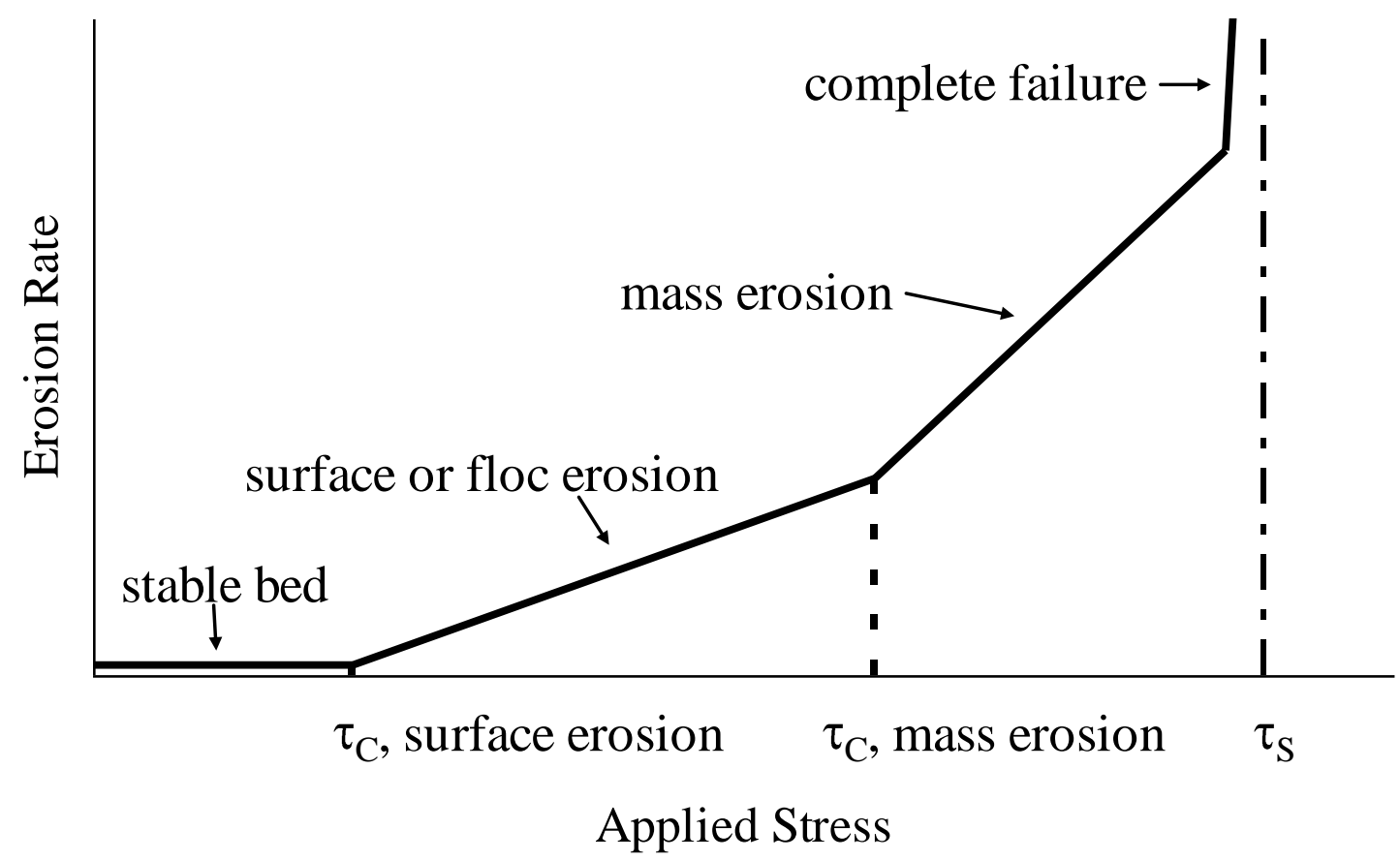

Figure 2.9. Graphical Qualitative Representation of the Erosion Rate as a Function of Applied Stress for a Single Material. Entrainment is not considered to be applicable to such a material and therefore, does not appear on the graph. 


\subsubsection{Fluid Injection}

Fluid injection includes a wide variety of phenomenon that can contribute to erosion. Fluid injection refers to the application of fluid to the bed at a location/s internal to the bed and not at a free surface. The source may be from a lance inserted into the bed or the result of groundwater flow. For erosion from fluid injection to occur, there must exist flow within the bed material. Therefore, one of the following conditions must exist.

- The pressure of the water source must be sufficient to initiate flow through the bed material.

- The pressure of the water source must be sufficient to cause the bed material to yield.

With fluid flow into the bed established, the following phenomenon may occur.

- Dissolution-Fluid flow can result in the dissolution of bed constituents. The dissolution of bed constituents can result in weakened bed strength, leading to additional forms of erosion resulting from the injection process.

- Material transport-The porosity of the bed is such that finer constituents can be transported through the bed. The erosion of the finer particulate may result in weakened bed strength.

- Bed fracture/yield - With liquid being injected into the bed, either the flowrate through the bed increases, or the bed must swell and or yield. Any increase in the flowrate within the bed will result in an increase in the pressure gradients and associated applied stresses within the bed. It is possible for the increased flow through the bed to exist without erosion or bed failure occurring. If the bed does yield, it can result in a catastrophic failure of the bed structure or single fractures by which the fluid can flow through and from the bed. In either case, after the occurrence of bed failure, it is possible for surface and mass erosion to occur along the flow paths through the bed.

- Fluidization-Fluidization occurs if uniform flow through the bed causes the bed to swell (i.e., the porosity to increase). The increase in porosity can be sufficient to eliminate any yield strength the bed had causing the bed to behave as a viscous fluid. The fluidization of the bed is similar to the phenomenon of entrainment.

- Cavern generation - Cavern generation is the formation of a mobilized region within the bed. There are numerous scenarios related to the formation of a mobilized cavern and the resulting erosion. The injected water can either flow through the bed material as it leaves the cavern, or the injection process can cause the bed to fracture or yield. If material is transported from the cavern, the solids concentration within the cavern will be reduced, aiding the growth of the cavern. The mobilized region of the cavern is a weak spot in the bed structure. If the cavern continues to grow, then the structural strength of the bed continues to be reduced until a catastrophic failure of the bed occurs.

- Chemical changes - The flow of fluid through the bed can result in chemical changes, such as chemical concentration and $\mathrm{pH}$. Depending on the makeup of the incoming fluid, the bed's resistance to erosion could be increased or decreased.

\subsubsection{Corrasion}

Corrasion is the erosion of particulate due to abrasion by free particulate being moved by the overlying fluid. Corrasion can occur because of particulate being readily transported by the fluid that passes along the material surface or periodically impacts the material surface as turbulent flow carries particulate into and away from the bed surface. Corrasion can also occur for existing solids too heavy to 
be fully transported away. Such instances can occur for reciprocating flows, such as waves or strong eddies (e.g., flow over a step or an impinging jet discharging into a depression, cavern, or scour hole). Solids causing corrasion can be transported to the surface by the eroding material or may have existed within the bed and were freed/dislodged as smaller size or lighter surrounding material was eroded away.

The magnitude of corrasion depends on the solids concentration at the material surface, particle size, particle density, particle shape, and the particle velocity at impact. Corrasion of cohesive materials occurs at the bed surface as the particulate scours the bed surface. The effect of corrasion on non-cohesive beds is to aid in dislodging particulate held in place by larger, heavier particles or tight packing.

Depending on the abrasive material, the effect of corrasion on a cohesive bed can be significant. During experimental investigations performed to examine the erosion effects of seashells, erosion rates increased from 5 to 20 times greater compared to similar conditions with no corrasion. (Amos 1999) The degree of corrasion depends on the physical properties of the abrasive material with the size of the abrasive material relative to the size of the bed material being a major factor. If the abrasive material is on the same order of size as the bed material, it is expected to have minimal impact on the erosion. However, the impact on erosion is anticipated to increase with the increase in the relative size difference.

The contribution of corrasion during retrieval of K-Basin waste will depend on the relative size and concentration of non-cohesive particulate contained within the waste. It is also important to note that even if relatively large particles exist within the waste, corrasion will not be a factor if the larger particles are readily removed (retrieved) from the bed surface upon being dislodged.

\subsubsection{Cavitation}

Erosion via cavitation occurs when gas/vapor bubbles collapse at the material surface. In the implosion of the bubble, a micro jet of liquid is created that travels at high velocity and large pressure, producing extreme stresses on a very small area of the bed surface. Cavitation occurs when the pressure within the flow falls below the vapor pressure of the liquid. This only occurs when the overlying fluid travels at a high velocity.

\subsubsection{Material Parameters}

Sections 2.2.2.2 and 2.2.2.1 list the parameters that characterize non-cohesive and cohesive materials, respectively. Section 2.3 will summarize those properties that are key to assessing the erodibility of the materials. The parameters associated with the overlying liquid include:

- Liquid density

- Liquid temperature-The erodibility of a bed is expected to increase with increasing temperature because of the increase in the Re, the reduced viscosity of the interstitial liquid, and the increased permeability associated with the reduced viscosity. Kelly and Gularte conducted experiments with illite clay at various temperatures. The erosion rate was found to increase by a factor of three over the temperature range $10^{\circ} \mathrm{C}$ to $30^{\circ} \mathrm{C}$. The results of the various studies associated with temperature effects are inconsistent and not conclusive (Winterwerp and Van Kesteren 2004).

- Liquid viscosity 
- $\mathrm{pH}$

- Additional chemical constituents and parameters that may affect the bonding strength or flocs of cohesive materials.

\subsubsection{Non-Cohesive Materials}

Parameters associated with the erodibility of non-cohesive materials include:

- Particle size and distribution

- Particle shape

- Particle density

- Void fraction or porosity

- Permeability

- Critical Shear Stress (critical shear stress for erosion) - The applied shear stress for which greater values result in the onset of erosion (refer to Section 3.2)

- Yield Stress in shear (also referred to as shear strength).

\subsubsection{Cohesive Materials}

Parameters associated with the erodibility of cohesive materials include:

- Particle size and distribution

- Particle shape

- Particle density

- Bulk density

- Void fraction or porosity

- Permeability

- Critical Shear Stress (critical shear stress for erosion) - The applied shear stress for which greater values result in the onset of erosion (refer to Section 3.2). For cohesive materials, many investigators have defined both a critical shear stress for surface erosion, $\tau_{\mathrm{c} 1}$, and a second critical shear stress for mass erosion, $\tau_{\mathrm{c} 2}$, where $\tau_{\mathrm{c} 1}<\tau_{\mathrm{c} 2}$ and $\tau_{\mathrm{c} 2} \leq \tau_{\mathrm{s}}$. Refer to Figure 2.9.

- Yield Stress in shear (also referred to as shear strength)

- Compressive Strength

- Hydraulic Conductivity

- Moisture Content

- Plasticity Index.

\subsubsection{Operational Conditions}

The following sections discuss operational issues that may impact the erosion of K-Basin waste during storage at T Plant or the assessment of hot cell samples. The current assumption is that the waste will be retrieved using a hydraulic jet/s to mobilize the waste. Section 2.2.3.1 addresses erosion via both 
impinging and wall jets. Sections 2.2.3.2 and 2.2.3.3 discuss issues associated with jet coherence and material heterogeneity, respectively.

\subsubsection{Jet Orientation}

The following discussion will assume circular, submerged, well developed (coherent) jets. The two orientations to be discussed are a vertical impinging jet and a wall jet with negligible standoff distance from the material. For this discussion, the nozzle centerline for an impinging jet is perpendicular to the material bed surface, and for a wall jet, the nozzle centerline is parallel to the surface of the material bed. Refer to Figure 2.10 and Figure 2.11.

The discussion will focus on the application of jets to erosion and not jet theory. Rajaratnam (1976) provides a thorough characterization of the flow fields produced by both jet configurations. An important factor to consider in the application of jets for erosion compared to a large portion of the published literature is the resulting flow field and thus the shear stress applied to the material surface. It appears that a majority of erosion studies rely on field data from channels and estuaries and laboratory data from flumes. The flow fields for these configurations are uniform flows with negligible acceleration whereas the flow from a submerged jet is mixing with the surrounding fluid, resulting in a decreasing velocity with downstream distance from the nozzle. This results in a non-uniform shear stress being applied to the material surface. Mazurek and Hossain (2007) conducted an investigation to assess the ability to predict material scour (erosion) in both cohesive and non-cohesive materials that is produced by flow from a circular jet. Their investigation included both impinging jets and wall jets, which are discussed in Sections 2.2.3.1.1 and 2.2.3.1.2, respectively.

\subsection{Impinging Jet}

For the impinging jet, the height, $\mathrm{H}$, of the nozzle discharge, of diameter $\mathrm{d}_{\mathrm{n}}$, above the material surface will be assumed to be large $\mathrm{H} / \mathrm{d}_{\mathrm{n}}>8.3$ (Beltaos and Rajaratnam 1977). For erosion by a fixed impinging jet in non-cohesive material, it is known that the main dimensions of the eroded void expand in a linear relation with the logarithm of time until an asymptotic state is achieved (Rajaratnam 1982). H will always be measured from the original elevation of the undisturbed bed.

The dimensions of the eroded void in non-cohesive material at an asymptotic condition are related to the ratio of the densimetric Froude Number, Fr (refer to the right-hand side of Equation 2.4, which is the square of Fr) and the dimensionless impingement height, $\mathrm{H} / \mathrm{d}_{\mathrm{n}}$. For the application to jets, $\mathrm{U}$ in Equation 2.4 is $\mathrm{U}_{0}$, the average discharge velocity from the nozzle.

The eroded void created by the jet can have a large or small aspect ratio of maximum depth, $\mathrm{h}_{\mathrm{m}}$, to radius, r. Large and small aspect ratios are referred to as being in the "strongly" and "weakly deflected jet regime," respectively, depending on the ratio $\mathrm{Fr} /\left(\mathrm{H} / \mathrm{d}_{\mathrm{n}}\right)$ (Mazurek and Hossain 2007). The $\mathrm{h}_{\mathrm{m}}$ will always be referenced from the original elevation of the undisturbed bed.

- For $\mathrm{Fr} /\left(\mathrm{H} / \mathrm{d}_{\mathrm{n}}\right)>0.35$, the jet will be in the "strongly deflected jet regime" (SD). In the $\mathrm{SD}$, the jet turns back on itself, and there is a significant concentration of particulate suspended by the flow within the eroded void. When the flow of the jet is terminated, the suspended material within the void settles, reducing the depth of the void from that obtained during flow. 
- For the "weakly deflected jet regime" (WD), the void is relatively much shallower and the concentration of particulate suspended by the flow within the eroded void is much less than in the SD case.

While the jet behavior and aspect ratios of the two regimes are different, the profiles are similar. An annular mound of material will be deposited around the lip of the voids. Aderibigbe and Rajartnam (1996) developed a dimensionless profile for the eroded void in non-cohesive material using the maximum depth of the void, $\mathrm{h}_{\mathrm{m}}$, as the scale for the void depth, $\mathrm{h}$, and the half-width, $\mathrm{w}$, as the scale for the radius of the void, which is given by

$$
\frac{h}{h_{m}}=\exp \left\lfloor-0.693\left(\frac{r}{w}\right)^{2}\right\rfloor
$$

The half width $\mathrm{w}$ is the radial distance of the void where $\mathrm{h}=0.5 \mathrm{~h}_{\mathrm{m}}$. Figure 2.10 contains a schematic of a scour hole for an impinging jet with the characteristic length scales diagramed.

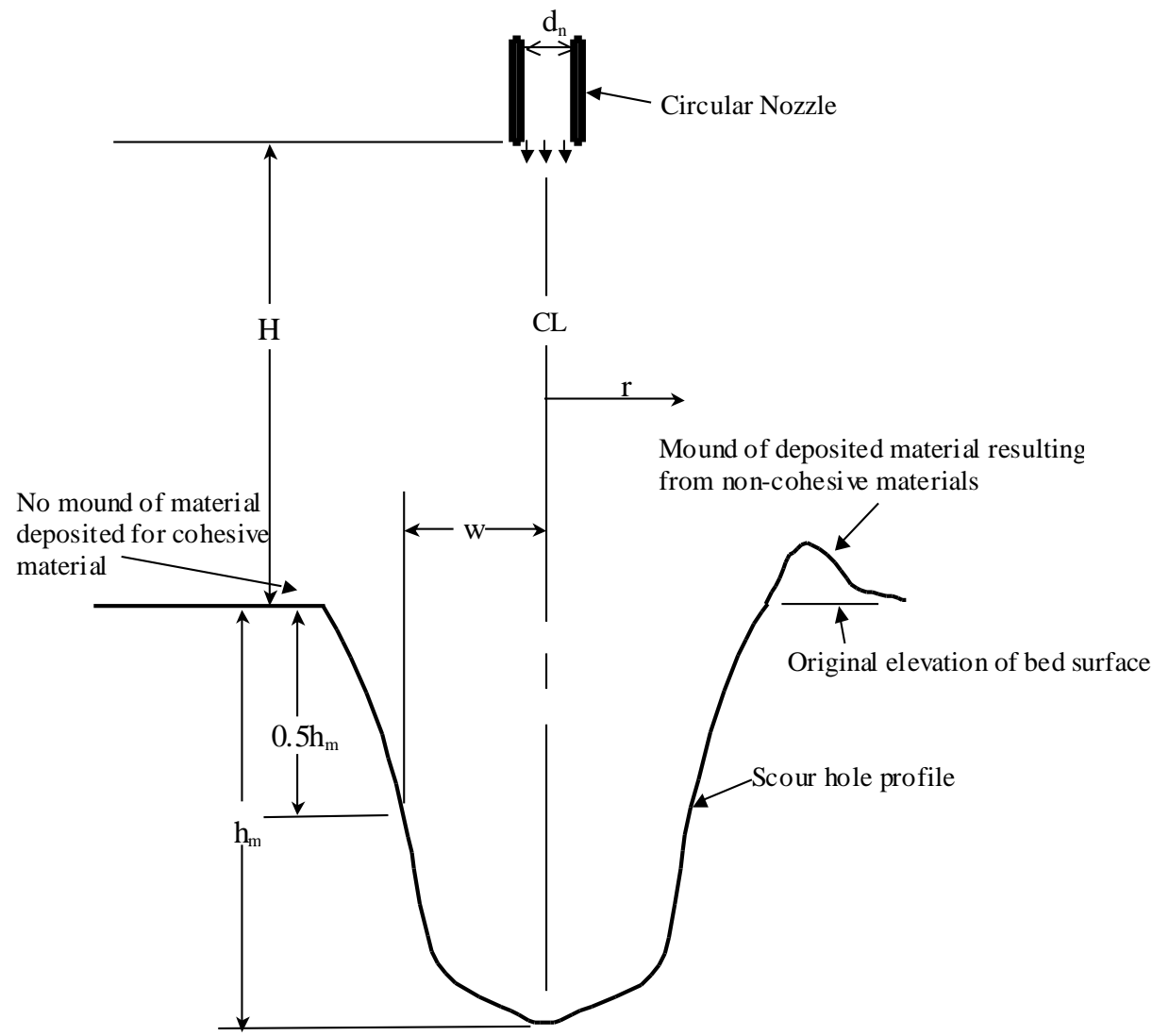

Figure 2.10. Diagram of Scour Hole Produced by Impinging Jet with Characteristic Length Scales Identified 
While Fr has been used to evaluate the scour of jets in non-cohesive materials, the same approach cannot be used in cohesive materials because the particle weight of cohesive material does not contribute to the erosion resistance (Mazurek and Hossain 2007).

For erosion by a fixed impinging jet in cohesive material, the main dimensions of the eroded void also grow in a linear relation with the logarithm of time until an asymptotic condition is reached. However, the growth of the void may be characterized by mass erosion, resulting in sudden jumps in void dimensions (Mazurek 2001). No mounds of material will build up around the lip of the eroded void, and the concentration of suspended material stays relatively low as it is readily flushed from the void. Mazurek (2001) determined that the main dimensions of the void at an asymptotic condition are a function of the dimensionless excess shear stress (refer to Section 2.2.1.3) applied by the jet at the surface of the bed at the start of erosion. Because of the non-uniform shear stress applied by a jet, the maximum shear stress is used to determine $\tau_{\mathrm{c}}$ and calculate the dimensionless excess shear stress. The equation for the maximum applied shear stress generated by an impinging jet on a smooth bed developed by Beltaos and Rajaratnam (1974) is

$$
\tau_{m}=0.16 \rho_{l} U_{o}^{2}\left(\frac{d_{n}}{H}\right)^{2}
$$

The smooth bed (surface) assumption is applicable for cohesive materials.

Mazurek (2001) found that the scour-hole profiles for non-cohesive and cohesive materials using the relationship of Equation 2.16 were similar out to $\mathrm{r} / \mathrm{w}>1.5$. However, comparing the scale for the dimensionless profile, $\mathrm{w}$, for the two types of material, it was observed that $\mathrm{w}$ for the cohesive material was larger than for non-cohesive material. This is not surprising since for the same value of excess shear, the cohesive material is more likely to be in the WD, where the eroded voids are wide and shallow (Mazurek 2001). The differences in the dimensionless profiles for $\mathrm{r} / \mathrm{w}>1.5$ may be the result of the different phenomenon within the eroded void for cohesive and non-cohesive materials.

The larger size particulate making up the non-cohesive material is not as readily transported from the void as the smaller cohesive material. This results in the concentration within the void for non-cohesive materials being greater. The increased concentration within the void results in

- A greater amount of material settling within the void when the jet flow is terminated. Therefore, for the non-cohesive material, there exists a dynamic void profile and a static void profile (Mazurek and Hossain 2007). This difference in static and dynamic conditions may explain the difference in the profiles beyond $\mathrm{r} / \mathrm{w}=1.5$ and needs to be considered if taking experimental measurements with noncohesive materials to determine $\tau_{\mathrm{s}}$.

- Jet energy that would otherwise work to erode the material being absorbed. This effect is greatest in the SD. Therefore, the erosion of the cohesive material with an impinging jet may be considered a more efficient process. This effect will be discussed further in Section 2.2.3.3.

\subsection{Wall Jet}

Consider a wall jet with a nozzle diameter $d_{n}$ oriented parallel to a material surface at a negligible height above the bed. The growth of the eroded void to an asymptotic state for both cohesive and non-cohesive materials behaves the same as for impinging jets. The void generated by the wall jet is an elongated 
trough that can be characterized by a maximum depth, $\mathrm{h}_{\mathrm{m}}$, the axial distance from the nozzle to the maximum depth, $\mathrm{x}_{\mathrm{m}}$, and the axial length of the entire void, $\mathrm{x}_{\mathrm{t}}$. Rajartnam and Berry (1977) and Ade and Rajartnam (1998) have shown that $h_{m}, x_{m}$, and $x_{t}$ depend primarily on the densimetric Froude Number (Mazurek and Hossain 2007). A schematic of a scour hole, produced by a wall jet, showing the characteristic lengths scales is diagramed in Figure 2.11.

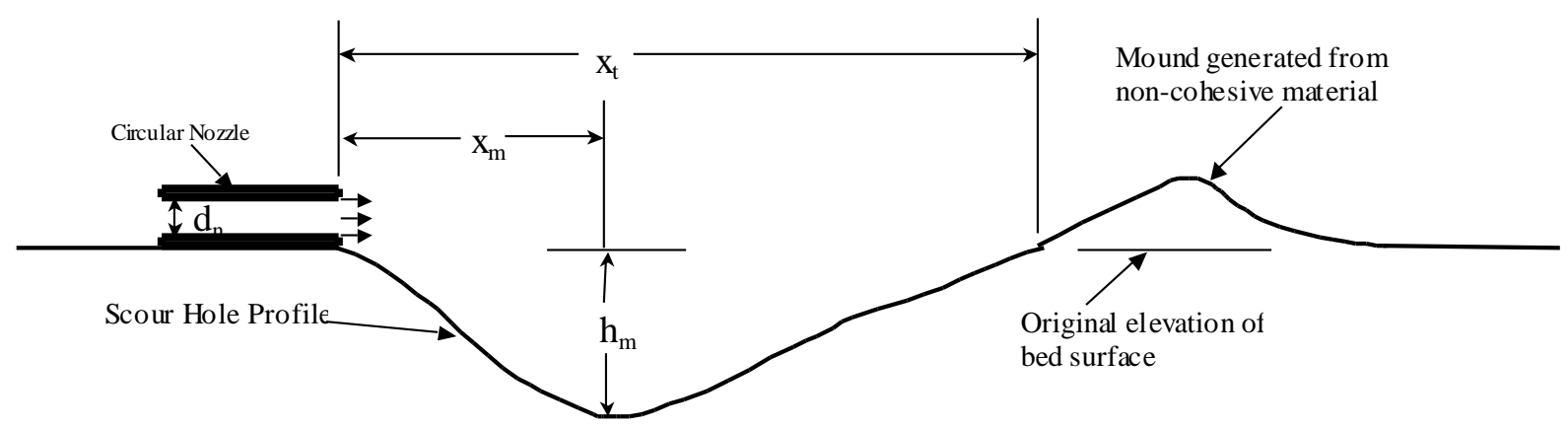

Figure 2.11. Diagram of Scour Hole Produced by Wall Jet with Characteristic Length Scales Identified

Mazurek et al. (2002) demonstrated that $\mathrm{h}_{\mathrm{m}}, \mathrm{x}_{\mathrm{m}}$, and $\mathrm{x}_{\mathrm{t}}$ for a cohesive material could be related to a dimensionless excess shear parameter. The equations for the applied shear stress generated by a circular wall jet on a cohesive material (Mazurek and Hossain 2007) is

$$
\tau=\frac{C_{f} \rho_{l} U_{o}^{2}}{2}
$$

where $C_{f}$ is the global skin friction coefficient. Mazurek and Hossain use a value of $C_{f}=0.003$ at $x / d_{n}=10$ based on the work of Rajaratnam and Pani (1974).

For non-cohesive material, the applied shear stress generated by a circular wall jet is

$$
\tau=\frac{c_{f} \rho_{l} U_{m}^{2}}{2}
$$

where $c_{f}$ is a local skin friction coefficient, and $U_{m}$ is the maximum velocity at a given downstream distance $\left(\mathrm{x} / \mathrm{d}_{\mathrm{n}}=10\right)$ from the nozzle. The localized skin friction coefficient, $\mathrm{c}_{\mathrm{f}}$, is a function of the relative roughness $\mathrm{k}_{\mathrm{s}} / \mathrm{d}_{\mathrm{n}}$ and was determined using the equation developed by Wu and Rajaratnam (1990). For their analysis, Mazurek and Hossain assumed $\mathrm{k}_{\mathrm{s}}=2 \mathrm{~d}_{\mathrm{p}}$.

\subsubsection{Jet Coherence}

Investigations associated with characterizing jet performance are usually performed with fully developed flows that produce a coherent jet flow closely approximating ideal conditions. Applications of jets in processes with geometric restrictions often do not produce a fully developed flow at the discharge of the nozzle. These less-than-ideal conditions often introduce a swirl component to the jet flow. The introduction of a swirl component causes the jet to spread/diffuse more rapidly, resulting in the velocity 
field decaying faster. This decay in the velocity field reduces the erosive capability of the jet by reducing the shear stress applied by the jet.

The introduction of a swirl component can also create a deflection in the path of the jet. While numerous operations are conducted using jets having a swirl component, the potential effects of swirl should be assessed in the design phase of a system or process to verify that the assumption of a coherent jet does not result in a system not meeting performance requirements.

\subsubsection{Heterogeneous Mixture}

The bulk of the literature and the prior discussions of erosion assumed homogenous materials. The condition of a larger particulate (non-cohesive) material being imbedded in a cohesive material needs to be considered. The non-cohesive material has the potential to create a greater condition of erosion resistance than was predicted based on material characterization or laboratory tests of the bulk material. Without going into significant detail, consider an erosion process applied to a heterogeneous material composed of both cohesive and non-cohesive material.

At the initiation of the process, the cohesive material is readily eroded. However, the non-cohesive particulate while mobilized is not readily transported from the bed (i.e., an impinging jet operating in the strongly deflected jet regime). The residual non-cohesive material has the potential to bury the remaining heterogeneous material under a material layer with an erosive resistance greater than the capacity of the erosion source.

To verify that the bounding condition for material erosion is understood, analyzing or testing the noncohesive portion of a heterogeneous mixture to assess its erodibility should be considered.

Heterogeneity is a contributing factor to the difficulties encountered in attempting to correlate material properties to predict erosive behavior. Slight changes in constituents or constituent concentrations can have a significant impact on material bulk properties while having negligible effects on the erosive resistance of a material bed. Consider a heterogeneous material like Sample 96-13 consisting of cohesive material (i.e a cohesive paste) and non-cohesive material consisting of larger size particulate. The cohesive paste will be the determining factor in the erodibility of the heterogeneous material due to an applied shear stress. However, changes in the concentration or particle size of the noncohesive material can have a significant impact on shear vane measurements conducted on the bulk material.

\subsection{Key Parameter Summary}

For non-cohesive materials, the key parameters for assessing the erodibility via surface jets are particle size, particle density, liquid density, and liquid viscosity. These parameters will allow the use of Shields' diagram or a related tool to determine the critical shear stress for the initiation of particle movement.

If the non-cohesive material contains a significant particle distribution, then the size distribution is important for determining a representative particle size to employ for determining $\tau_{\mathrm{c}}$. If the material contains multiple constituents, then analysis will need to be conducted to determine a representative 
density. Care should be taken to assess the sensitivity of the results to variation in the particle density, which will be dependent on the particle Re.

For cohesive materials, the material yield stress in shear (shear strength) provides an upper bound for the applied shear stress necessary to initiate materials erosion. The critical shear stress provides a lower bound for the applied shear stress required to initiate erosion.

Equations 2.6, 2.7, and 2.8 provide correlations for predicting the critical shear stress of cohesive materials from the bulk density, plasticity index, and combination of yield stress and plasticity index, respectively. However, the global application of these correlations is in question.

The additional parameters presented in Section 2.2.2.2 provide insight for comparing the potential erodibility of a material based on measurements for another. However, there currently does not appear to be all-encompassing tools for predicting the erosion of a material without obtaining data for similar or related types of material. It also worth noting that while measurements of shear strength, critical shear stress, and erosion rate have been reported extensively within the literature, investigations where all three parameters were measured were not readily found. 



\subsection{Parameter Measurement}

Selected measurement techniques for the key parameters for sediment erosion identified in Section 2 are discussed. In Section 3.1, traditional shear strength measurement techniques as well as those developed to understand Hanford waste are summarized. Techniques to determine critical shear strengths for erosion and erosion rates are discussed in Section 3.2.

\subsection{Shear Strength Measurements}

The yield stress in shear or shear strength may be defined as the point at which the sediment material ceases to deform like a solid under applied stress, but instead flows like a truly viscous material with a finite viscosity. Numerous techniques to determine a material's shear strength have been developed.

A review of both direct (direct assessment of the point at which the material yields or starts to flow) and indirect (extrapolation of shear stress-shear rate data to zero shear rate) techniques is presented by Nguyen and Boger (1992). Typical ex-tank measurements at Hanford are made with a shear vane (direct) or Couette type viscometers (indirect). Shear strength estimates for Hanford waste have been made based on horizontal waste core extrusion behavior (Gauglitz and Aiken 1997; Rassat et al. 2003). A pocket soil penetrometer has been used to estimate the shear strength of K-Basin sludge (Delegard et al. 2007).

\subsubsection{Couette Viscometer}

A Couette flow viscometer operates by measuring the shear stress resulting from an applied strain rate (stress-controlled viscometers are also employed). A typical configuration is the fluid of interest contained in a gap between two concentric cylinders wherein the inner cylinder is rotated. With a gap that is very small relative to the radius of the inner cylinder and the assumptions that 1 ) there is no pressure gradient in the flow direction and 2) there is no slip between the fluid and the boundaries, the shear stress is constant across the gap. Thus, the viscosity of the fluid is the shear stress divided by the strain rate. The yield stress in shear is determined by extrapolating the shear stress-shear rate data to zero shear rate.

As discussed in the literature (Nguyen and Boger 1983 and 1992; Barnes 1999), Couette viscometer data at low shear rates suffer due to the sensitivity of the instrument and additional shearing and slip caused by the configuration of the instrument. The model assumed (e.g., Bingham and Casson) for the data to extrapolate to zero strain rate can also affect the results (Nguyen and Boger 1992; Chhabra 1992). The data presented in Tingey et al. (2003) demonstrate for those Hanford wastes they considered that the waste has overshoot behavior, resulting in under-prediction of the yield point if the traditional models are applied.

Additionally, as has been noted in the referenced literature and with Hanford sediment (Onishi et al. 2003), sample disturbance history can have a direct impact on the measured shear stress. Aside from sample history before introduction into the viscometer, the configuration of the Couette viscometer itself may therefore also preclude the applicability of yield stress in shear estimates from this device to in situ conditions. The physical characteristics of the 96-13 sample as described in Section 2 are expected to preclude this measurement approach. 


\subsubsection{Shear Vane}

Issues with the Couette-type viscometers, such as slip and the sensitivity at low rotational speeds, may be resolved by the use of a rotating vane device. After a vane is immersed in a sample, the vane is slowly rotated, in effect rotating a cylinder of the material within itself. Torque on the vane shaft resulting from the resistance of the material to shear along the cylinder walls can be converted to shear stress, and shear stress as a function of time is recorded. The shear stress maximum is defined as the shear strength. The stress maximum, the transition between visco-elastic and fully viscous flow, is defined as the shear strength.

The shear vane methodology is used in a wide range of applications and materials and is widely used in the literature as a standard by which other shear strength measurement techniques are judged. However, although the shear vane sample configuration is more representative of in situ conditions than that of the Couette viscometer, the sample history may still have significant impact on the results (e.g., Gauglitz and Aiken 1997).

The investigation (Burns et al. 2009) of the portable torque/vane system procured by the Sludge Treatment Project (STP) to obtain in situ shear strength measurements also demonstrated that the material's level of heterogeneity may impact the representativeness of the shear vane results. Poloski et al. (2006) demonstrated that vane immersion depth and sample container size had a si gnificant effect on shear strength measurements for powders and slurries containing coarse particles. Ancey and Jorrot (2001), investigating relatively weak clay dispersions with coarse particulate fractions, note that the coarse fraction renders the use of laboratory rheometers for yield stress in shear "difficult." The heterogeneity of sample 96-13 (Section 2), appearing to contain "chunks" of hard material, may influence shear vane results for that sample.

\subsubsection{Waste Core Extrusion Behavior}

Gauglitz and Aikin (1997) developed a methodology to determine the shear stress of Hanford waste sediment based on a visual comparison of horizontal waste core extrusion behavior for simulants with known shear strength to that of Hanford Waste. Their results generally agreed within a factor of two with the in situ ball rheometer data (the ball rheometer is an in situ device developed for deployment at Hanford; Stewart et al. 1996).

An "extrusion length" methodology based on the simulant extrusion data of Gauglitz and Aikin (1997) for estimating the yield stress in shear of Hanford Waste was developed in Rassat et al. (2003). This methodology relies on measuring the initial extrusion length of the waste core at plastic failure and produces shear strength values similar in magnitude and with similar trends as the ball rheometer results. It was concluded that, in the absence of definitive in situ measurements, or in support of them, this methodology is expected to produce representative results for the waste shear strength. Although both of the waste core extrusion estimates rely on ex-tank core extrusion behavior, they are as representative of $i n$ situ conditions as is available ex-tank.

Direct application of the waste extrusion methodologies to K-Basin material such as sample $96-13$ is challenging given the sample configuration. As noted in Tingey et al. (2003), the extrusion scale may be expected to affect the results. The current range of applicability of the methodologies is also limited to 
shear strengths on the order of 10,000 $\mathrm{Pa}$ (maximum simulant shear strength employed by Gauglitz and Aiken [1997] was 6,500 Pa).

\subsubsection{Soil Penetrometer}

A pocket soil penetrometer was used by Delegard et al. (2007) to measure the unconfined compressive strength (UCS) of the hydrothermal testing of K-Basin samples. The penetrometer measurement is conducted by pressing the penetrometer probe a specified depth into the sample. The resulting UCS value can be converted to shear strength by dividing by 2 as presented in Delegard et al. (2007) (from Holtz and Kovacs 1981).

Although the soil penetrometer has been successfully deployed in K-Basin samples, the application may be limited by sample quantity (sufficient sample to impinge the device without boundary effects is required). Delegard et al. (2007) noted that brittle materials challenge the penetrometer methodology. Heterogeneity in the material can obviously influence the results.

While the relation of shear strength equaling UCS/2 has been supported by practice as well as experimentation and numerical results (Tanaka 1994, 2002; Tsuchida 2000; Fredlund and Vanapalli 2002), it is not universally accepted. Billam (1977) notes that vane and penetrometer results cannot be directly related because each causes a different failure mechanism. The relation of penetrometer UCS to shear strength for K-Basin materials may be investigated by taking penetrometer measurements on the K-Basin simulants employed by Burns et al. (2009). Direct comparison of the penetrometer results can then be made to the shear vane results of Burns et al. (2009).

\subsection{Critical Shear Strength for Erosion}

The concept for experimentally determining the critical shear strength for erosion is to experimentally observe the highest fluid velocity for a geometrical configuration at which erosion does not occur and then to calculate the corresponding applied shear stress from the known velocity and geometry. One of the issues associated with the critical velocity is that it has not been consistently defined. It is impossible to directly measure a phenomenon that does not occur (the maximum velocity at which no erosion occurs). Most definitions from past work have relied on direct visual observations, which can be highly subjective (Simons and Senturk 1992). Some of the following criteria, as summarized in Hobson (2008) and in Simons and Senturk (1992) include:

- The initial visual observation of localized particle motion (for non-cohesive materials). Kramer (1935) defined three types of bed material motion:

○ Weak movement: Only a few particles are in motion on the bed. The particles moving within $1 \mathrm{~cm}^{2}$ can readily be counted.

o Medium movement: The particulate of mean diameter begin to move. The motion is not local in character, but the bed continues to be a flat plane.

o General movement: All the mixture is in motion; the movement is occurring over all parts of the bed at all times.

- The visual observation of the onset of erosion; removal of bed material.

- The change or measurement of a predetermined degree of turbidity in the overlying fluid. 
- The occurrence of a specified amount of erosion within a prescribed duration (e.g., $1 \mathrm{~mm}$ within 5 minutes).

- The measurement of erosion rates for various applied shear stresses greater than $\tau_{\mathrm{c}}$ and the determination of the critical shear stress (zero erosion rate) by fitting of the data.

- The measurement of geometrical dimensions of eroded voids for various applied shear stresses greater than $\tau_{\mathrm{c}}$ and the determination of the critical shear stress (zero erosion rate) by fitting of the data.

For non-cohesive materials, the Shields diagram or a similar form, which relates a dimensionless shear stress to a boundary Reynolds Number, is often used to determine $\tau_{\mathrm{c}}$. The need to experimentally determine $\tau_{\mathrm{c}}$ arises when the bed particle size and/or particle density is not well defined because of dispersed particle size and/or multiple constituents.

Two of the most common apparatuses for assessing erosion rates and critical shear stress both in the laboratory and in situ are flumes and impinging circular jets. Flumes provide a steady constant horizontal flow across the test bed material. Flumes can include features such as:

- Adjustable slope

- Adjustable surface roughness

- Adjustable height of the material bed being eroded so the eroding surface stays at a constant elevation within the flume. The test material container can be extruded as material is eroded. The extrusion rate can be monitored, thus obtaining erosion depth measurements as a function of time while maintaining a fixed geometry.

For a flume, the applied shear stress is

$$
\tau=\frac{A_{x} \rho_{l} g}{P_{w}} \sin \theta
$$

where $A_{x}$ is the cross-sectional flow area, $P_{w}$ is the wetted perimeter, and $\theta$ is the inclined angle of the channel ( $\theta=0$ for a horizontal channel) (Blevins 1992). Equation 3.1 is applicable to uniform channel flow (i.e., no acceleration).

Impinging jet measurements are performed with a submerged, downward-directed, vertical circular jet. The axis of the jet flow is perpendicular to the material surface refer to Figure 2.10. Some devices are configured to allow the jet to be pulsed for a prescribed duration. One such device, called a cohesive strength meter (CSM), developed by Tohurst et al. (1999), was calibrated using sieved quartz sand and reproduced values obtainable from a Shields diagram. The submerged jet is positioned above the test bed at a relatively large impingement height, $\mathrm{H} / \mathrm{d}_{\mathrm{n}}>8.3$ (Beltaos and Rajaratnam 1977). The calculation of the maximum shear stress applied by an impinging jet on a smooth surface is provided in Equation 2.16. For non-cohesive materials, the determination of the maximum applied shear stress for an impinging jet has not been clearly defined because of factors associated with the scouring of non-cohesive materials using the geometric configuration of an impinging jet. Refer to Section 2.2.3.1. 
For an impinging jet, the erosion rate can be difficult to monitor or determine because of the geometry of the eroded void. However, characteristics of the resulting scoured impression (void) can be characterized at an asymptotic state (refer to Section 2.2.3.1). To obtain the critical shear stress for erosion, 1) the velocity corresponding to the observed criteria for the initiation of erosion is determined, and the corresponding applied shear stress is calculated from a relationship such as Equation 2.16 for cohesive materials or 2) data for characteristics dimensions of the scoured impression at an asymptotic state as a function of discharge velocity are used to predict a zero (no erosion) dimension for the scoured void.

The same approach as that used for impinging jets has been applied for a circular wall jet (Mazurek and Hossain 2007). The configuration of a wall jet has the axis of flow parallel to the material surface, refer to Figure 2.11. The circular wall jet is placed directly on the bed. For the data examined by Mazurek and Hossain (2007), good comparison was observed between the results for cohesive and noncohesive materials in comparing the non-dimensional geometric dimensions of the asymptotic scoured voids as a function of the non-dimensional excess shear. The comparisons were made for circular wall jets using Equation 2.17 and 2.18 for cohesive (smooth surface material) and non-cohesive material, respectively.

\subsubsection{Proposed Method for Obtaining Critical Shear Stress in Hot Cell}

The following is a proposed concept for assessing the erodibility of waste samples and potentially obtaining critical shear stress measurements on sample size quantities of material within a hot cell. The purpose of the section is only to introduce the idea that conducting such tests is possible in the hot-cell environment. A qualitative erosion assessment was previously performed in the hot cell using an agitator in an open beaker with small, unconstrained, chunks of material (Delegard et al. 2007). The assessment was qualitative and the test setup, operating instructions, and data recording had not been optimized. This work is discussed in Section 4.2 where an attempt is made to obtain a gross estimate of the critical shear stress based on the available test records.

Erosion tests would involve generating a homogenous (i.e., without stratification of constituents) layer of solids followed by exposure of that layer to a known flow field for which the applied shear stress can be determined. The homogenous layer (i.e. test bed) would be created by filtering a small quantity of the material of interest using a stainless steel filter element to collect a deposited test bed.

The test bed would be placed in a test vessel such as a baffled beaker. The layer would be developed such that its liquid content replicates in situ conditions (rheological properties are a function of liquid content; see Gauglitz et al. 2009). If the material was insufficiently consolidated, additional pressure would be physically applied to achieve additional consolidation of the solids. After consolidation (if required), any excess loose material would be decanted from the slurry.

The first set of tests would examine the applied stress required to mobilize material from the test bed using a previously characterized flow field such as that produced by a paddle wheel or pitched blade turbine. The configuration of the vessel will be designed to allow the shear rate at the surface of the test material to be determined and confirmatory tests would be conducted before deployment in the hot cell. Depending on the configuration and size of the impeller, the resulting flow field, and the material surface either Equation 2.16 or 4.4 may be applicable for determining $\tau$. However, the final geometry will need to be evaluated and tested to determine the best relationship to use for calculating the applied shear stress. 
The applied shear stress would be controlled by varying the agitator speed. A schematic of a proposed concept is presented in Figure 3.1. After exposure to a given shear rate for a specified period of time, the slurry over the test bed would be decanted and analyzed, including undissolved solids (UDS)

measurements, to determine the rate of erosion. This would then be repeated for higher mixing energies.

A second set of tests would employ the same deposition method to create a test bed, but would use a small jet of known energy to provide the erosive force. These tests would be similar; the jet would be used to erode the material to an asymptotic state, followed by decanting the quantity of fluid and measuring the concentration of material that had been mobilized from the deposited layer. Depending on the jet geometry the equations of Section 2.2.3.1 may be applicable. Additional tests would be conducted at increasing jet velocities. A fit of the data for the cumulative mass removed for each condition would be performed to determine a zero erosion condition. From these two sets of experiments, it is anticipated that a rate of erosion as a function of shear rate and the critical shear rate could be determined.

The generation of the test bed via filtering is intended to provide a relatively homogeneous material that will allow for constant erosion rates to be determined and repeat tests to be conducted. However, the waste material retrieved and collected in the storage canisters will be subject to material segregation during settling. Testing would be conducted on stratified samples obtained via settling to determine if any of the segregated layers of materials presented significant challenges for material erosion. It is anticipated there is no practical means of separating the different layers of settled material. Therefore, the erosion resistance of the material will need to be monitored as a function of test bed depth. 


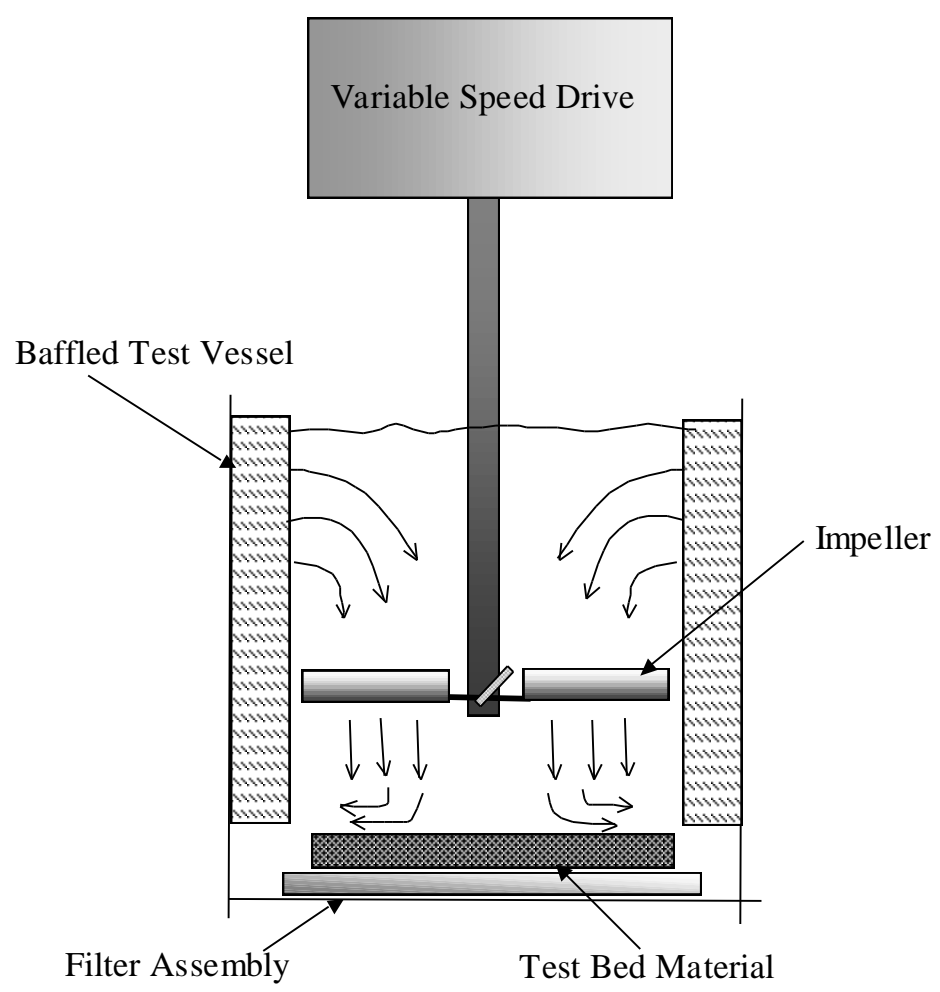

Figure 3.1. Schematic of a Conceptual Test Apparatus for Hot-Cell Erosion Assessment 



\subsection{Sample 96-13 Assessment}

The shear strength of sample 96-13 is estimated in Section 4.1 based on visual observation of the 96-13 sample settling study disassembly video. The erosion of K-Basin samples is considered in Section 4.2.

\subsection{Sample 96-13 Shear Strength Estimates}

As summarized in Section 2.3, a cohesive material's shear strength provides an upper bound for the applied shear stress necessary to initiate material erosion. The 96-13 sample settling study disassembly video has been reviewed in detail to identify potential instances where shear strength estimates can be made. In Appendix B of Gauglitz et al. (2009), the shear strength of Hanford sediment at the static equilibrium of a sludge weight or densitometer in that sediment is estimated. The approach relates compressive strength to shear strength. Thus, actions on sample 96-13 that may be used to estimate the shear strength include direct impingement of an object into the material. The identified instances where shear strength estimates can be made are listed in Table 4.1.

In Section 2, the 96-13 sample is characterized as a heterogeneous cohesive sediment with "paste" material joining "chunks." The descriptions in Table 4.1 refer to this characterization, and the "piece" for

estimates 5 and 6 is a combination of paste and chunks. Figure 4.1 through Figure 4.13 provide visual reference for the shear strength estimates. 


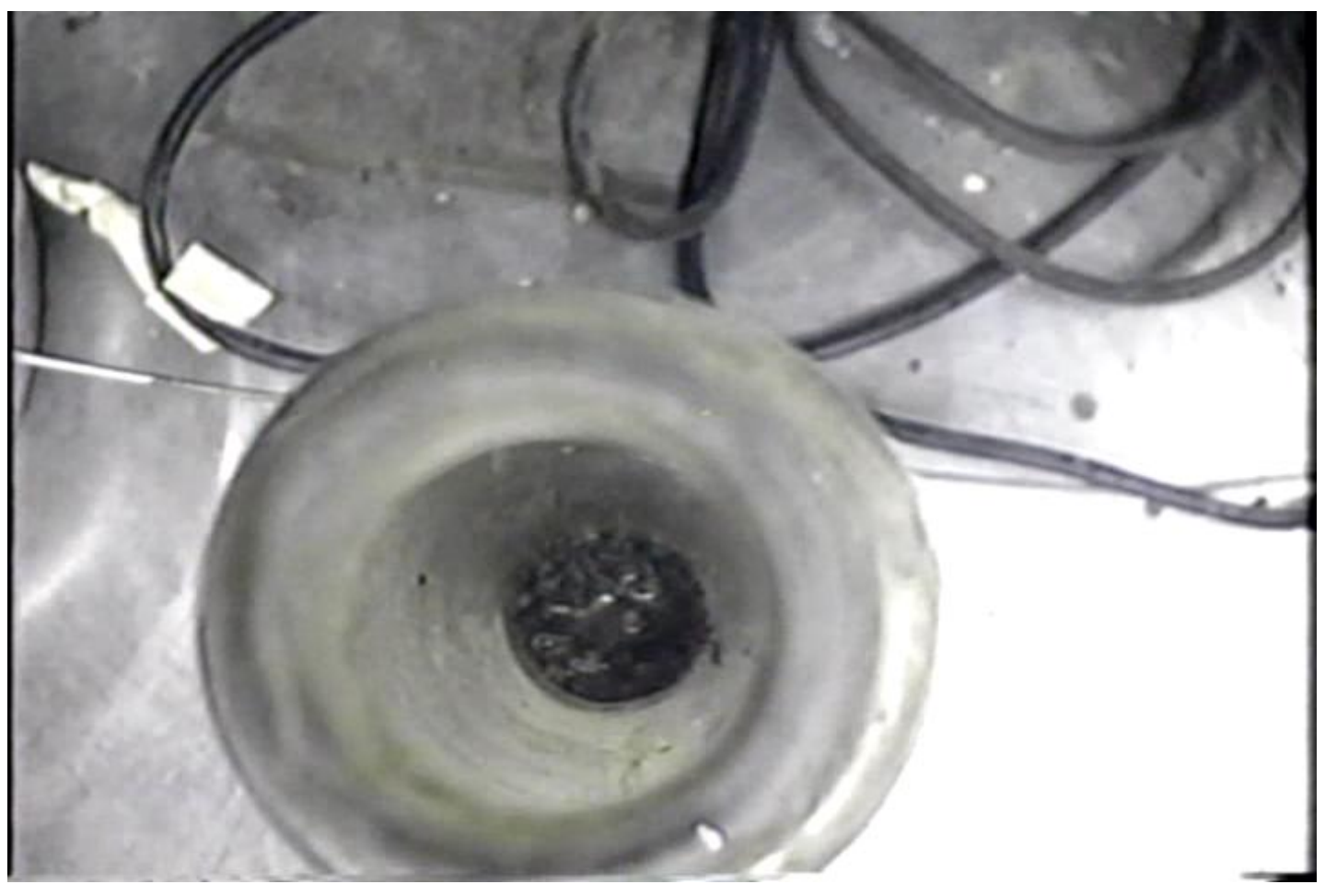

Figure 4.1. Sample 96-13 Shear Strength Estimate 1. Top View in Graduated Cylinder.

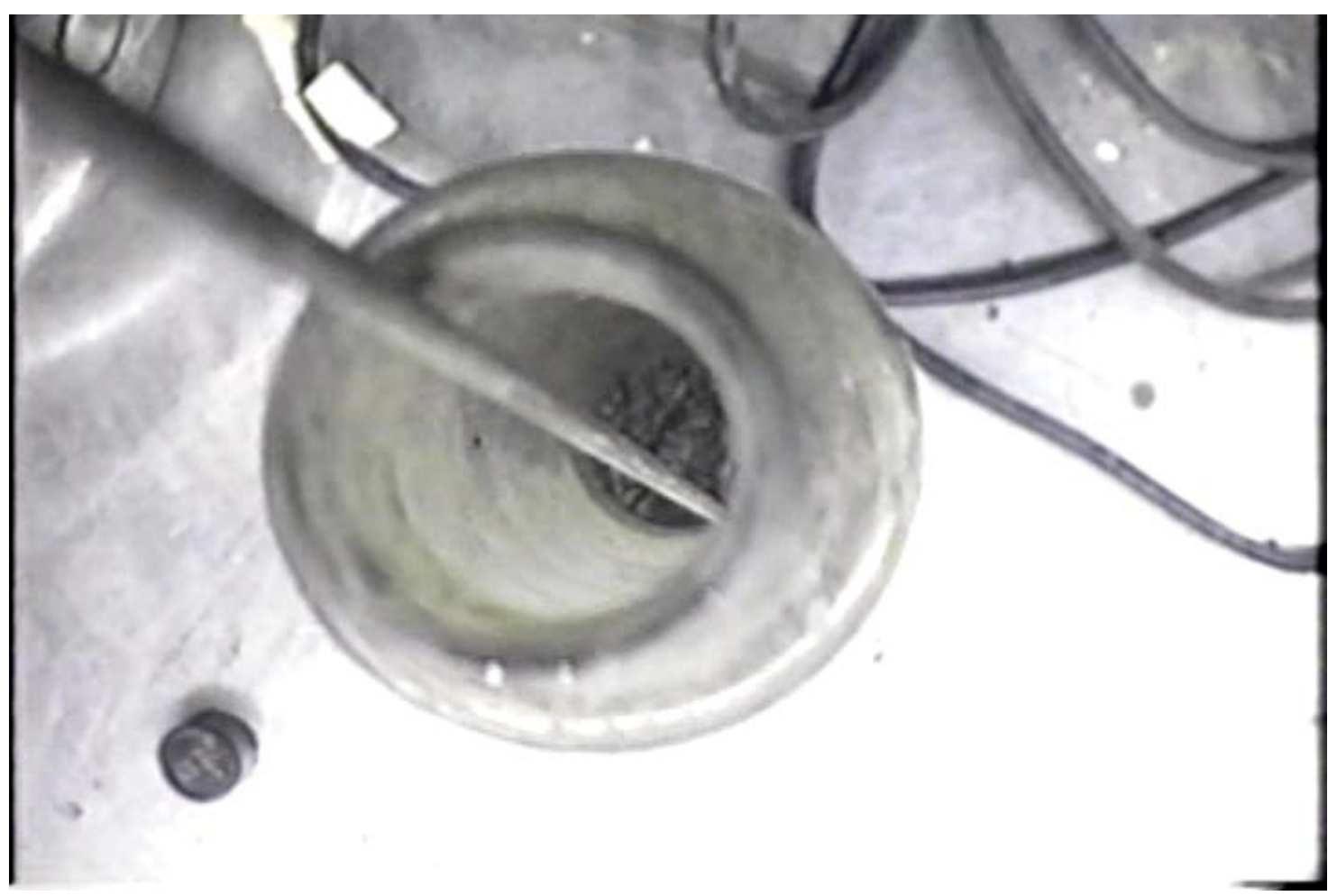

Figure 4.2. Sample 96-13 Shear Strength Estimate 1. Spoon blade is at lower right; "imprint" of spoon blade tip appears to be visible at center. 


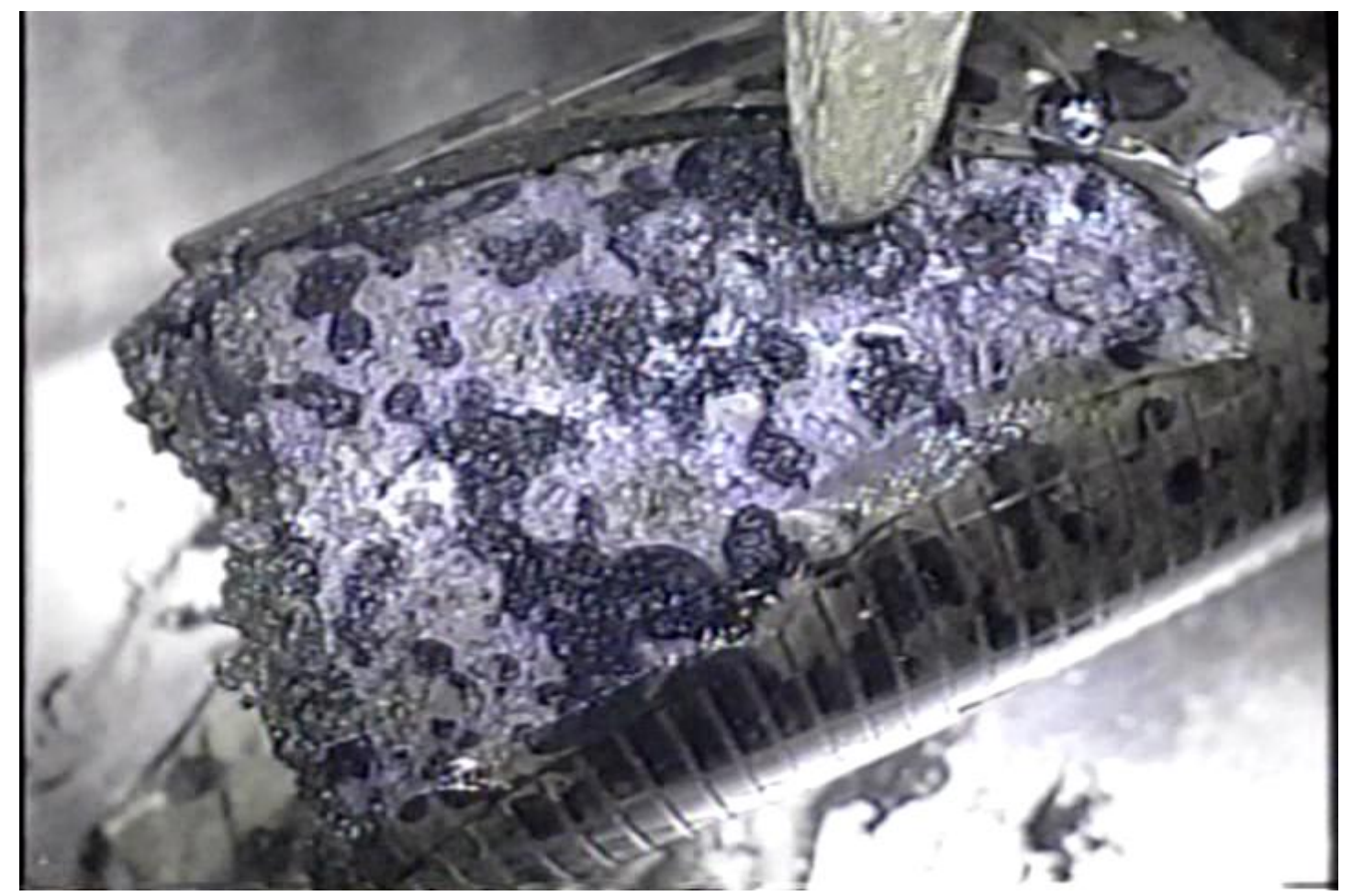

Figure 4.3. Sample 96-13 Shear Strength Estimate 2. Start of forceps impingement.

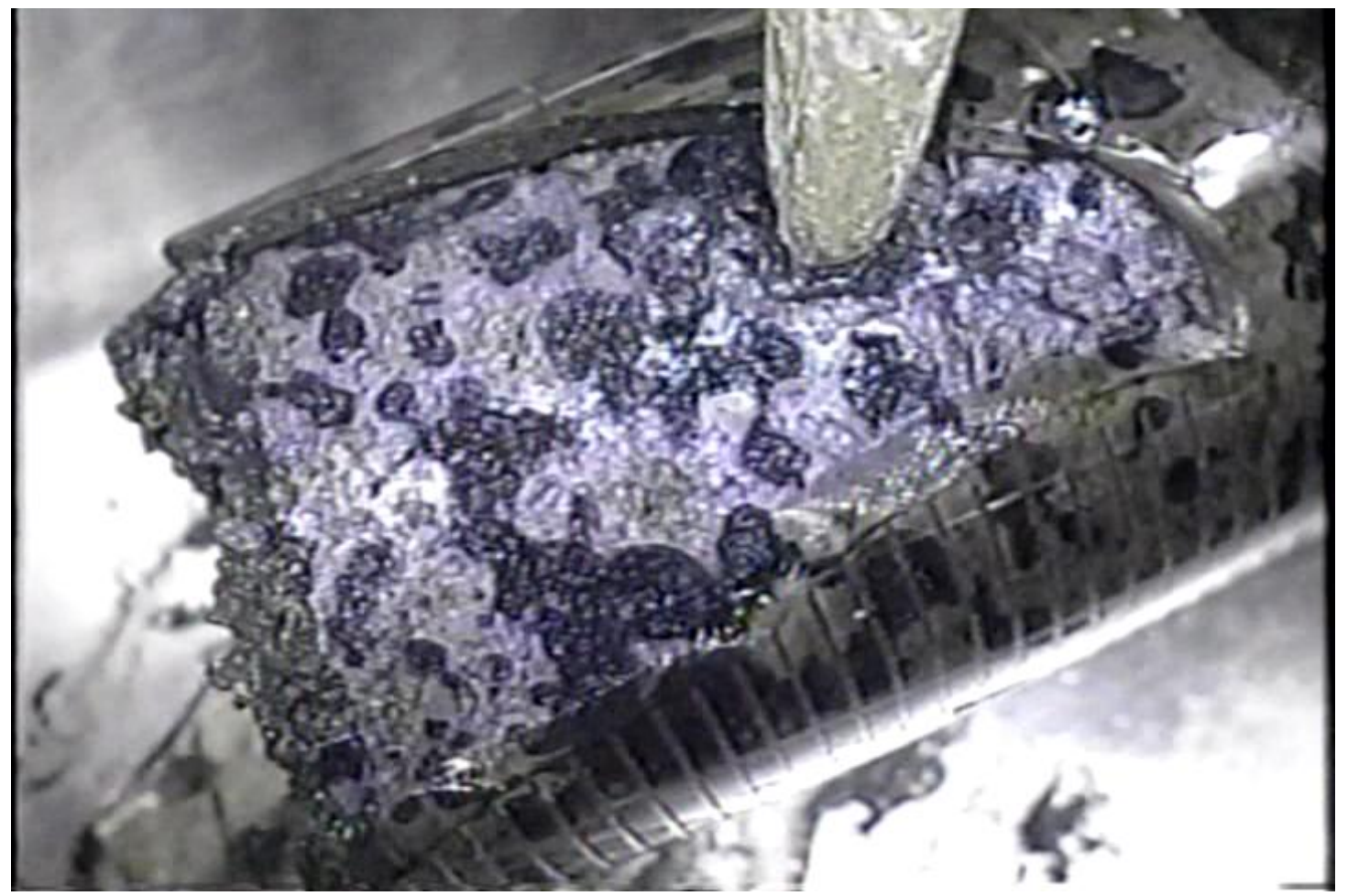

Figure 4.4. Sample 96-13 Shear Strength Estimate 2. Impingement of forceps tip evident. 


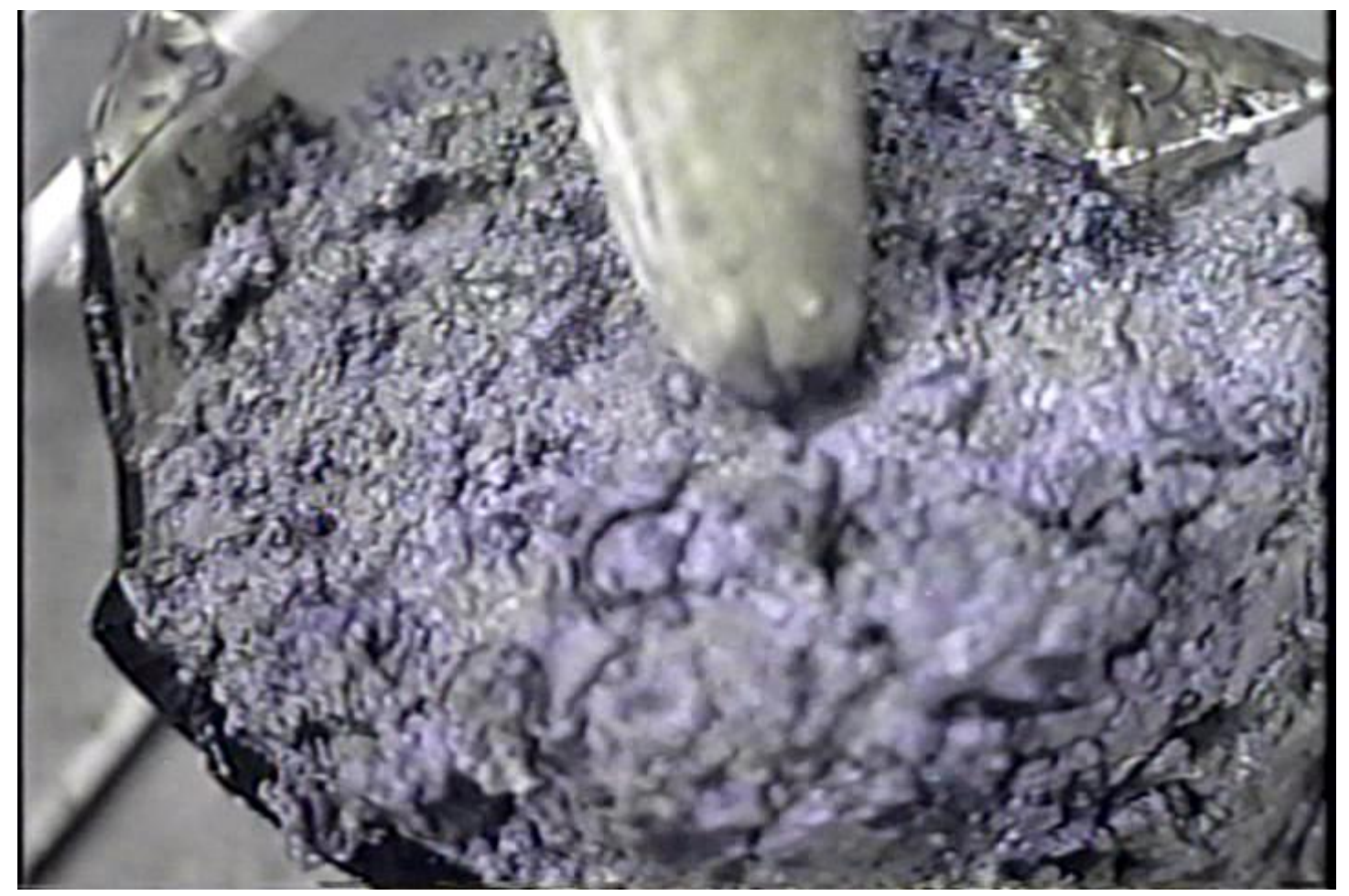

Figure 4.5. Sample 96-13 Shear Strength Estimate 3. Start of forceps impingement.

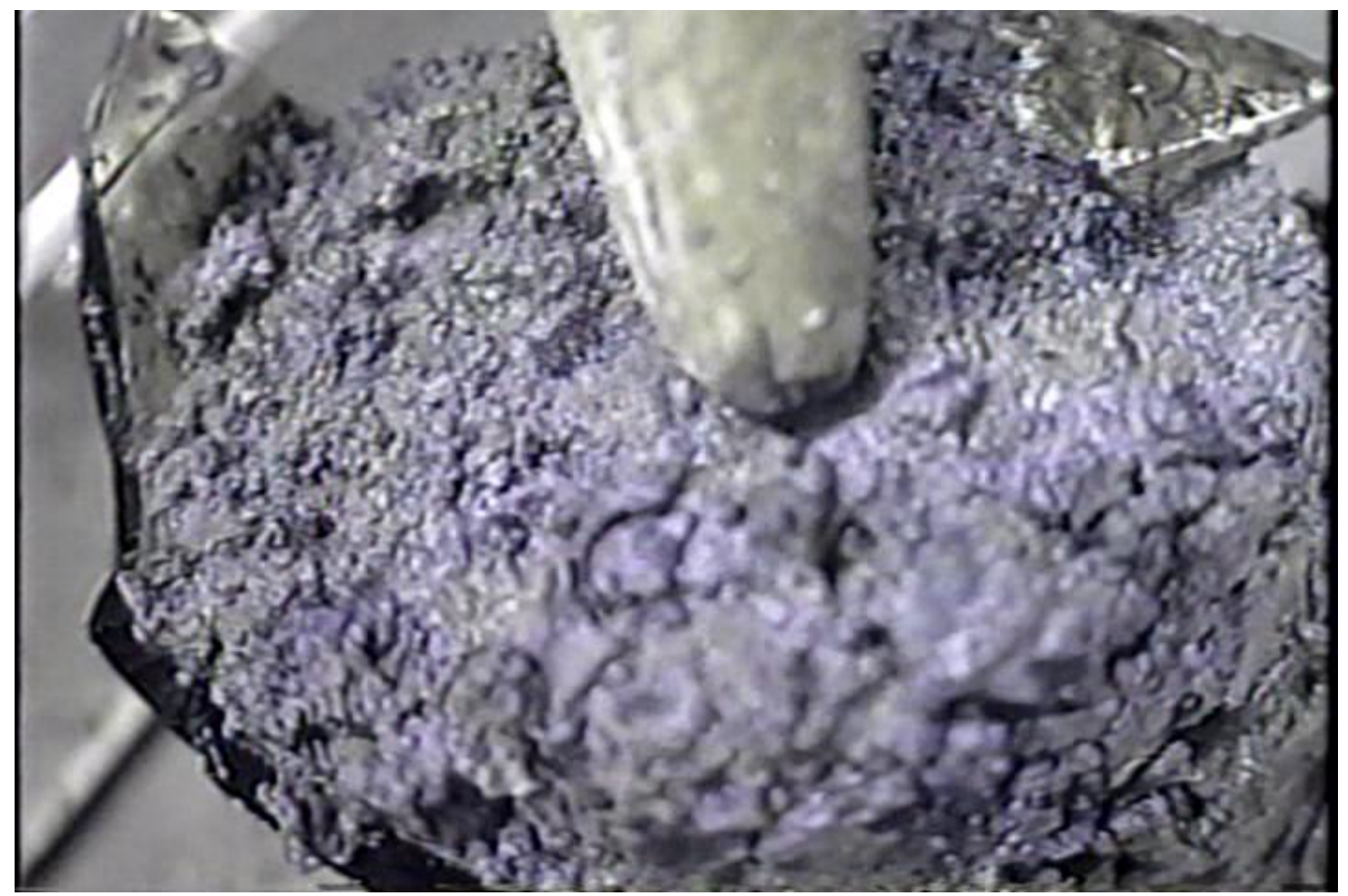

Figure 4.6. Sample 96-13 Shear Strength Estimate 3. Impingement of forceps tip. Although not observable in still photos, material movement away from the impingement site was observed. 


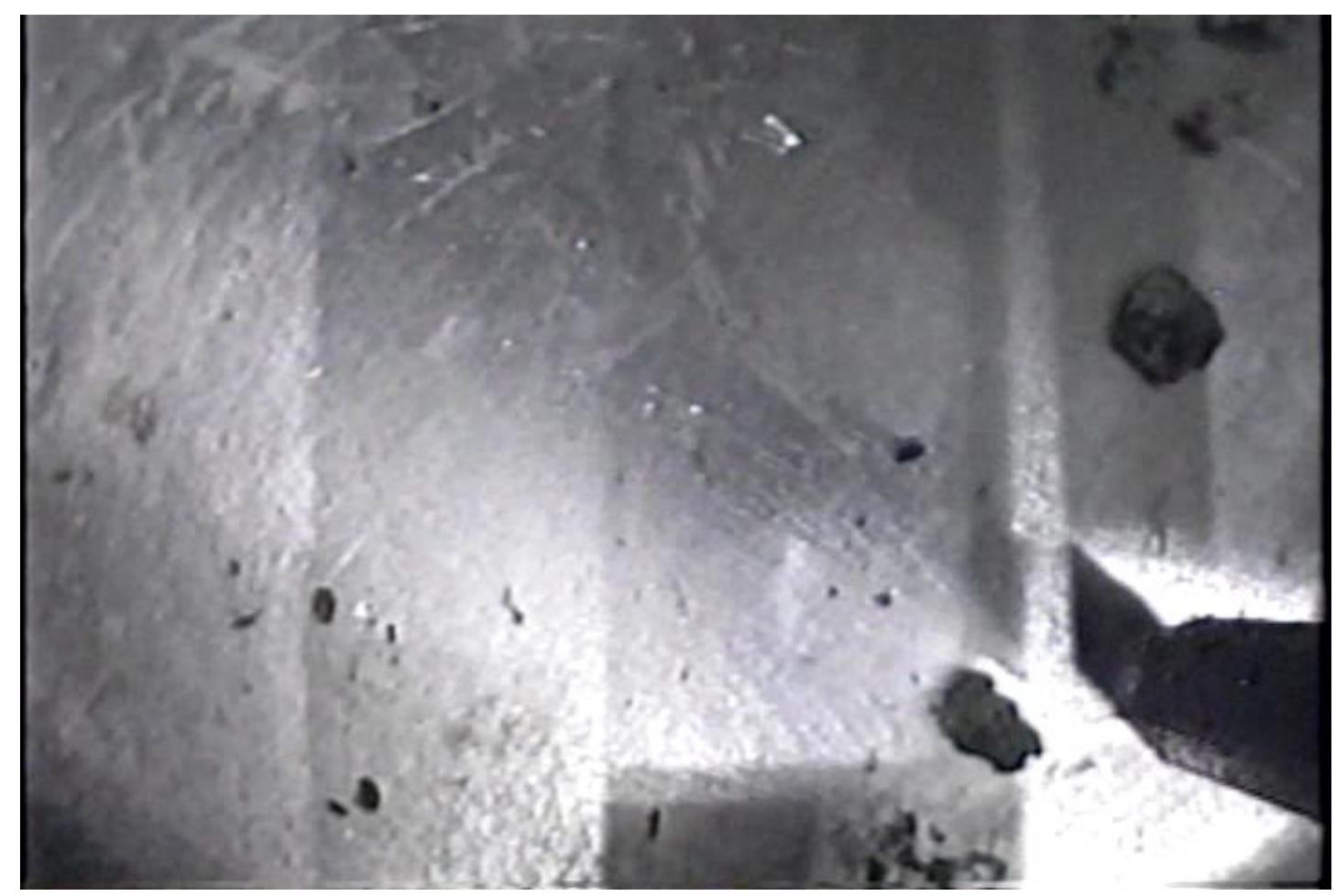

Figure 4.7. Sample 96-13 Shear Strength Estimate 4. Chunk prior to contact with hex wrench.

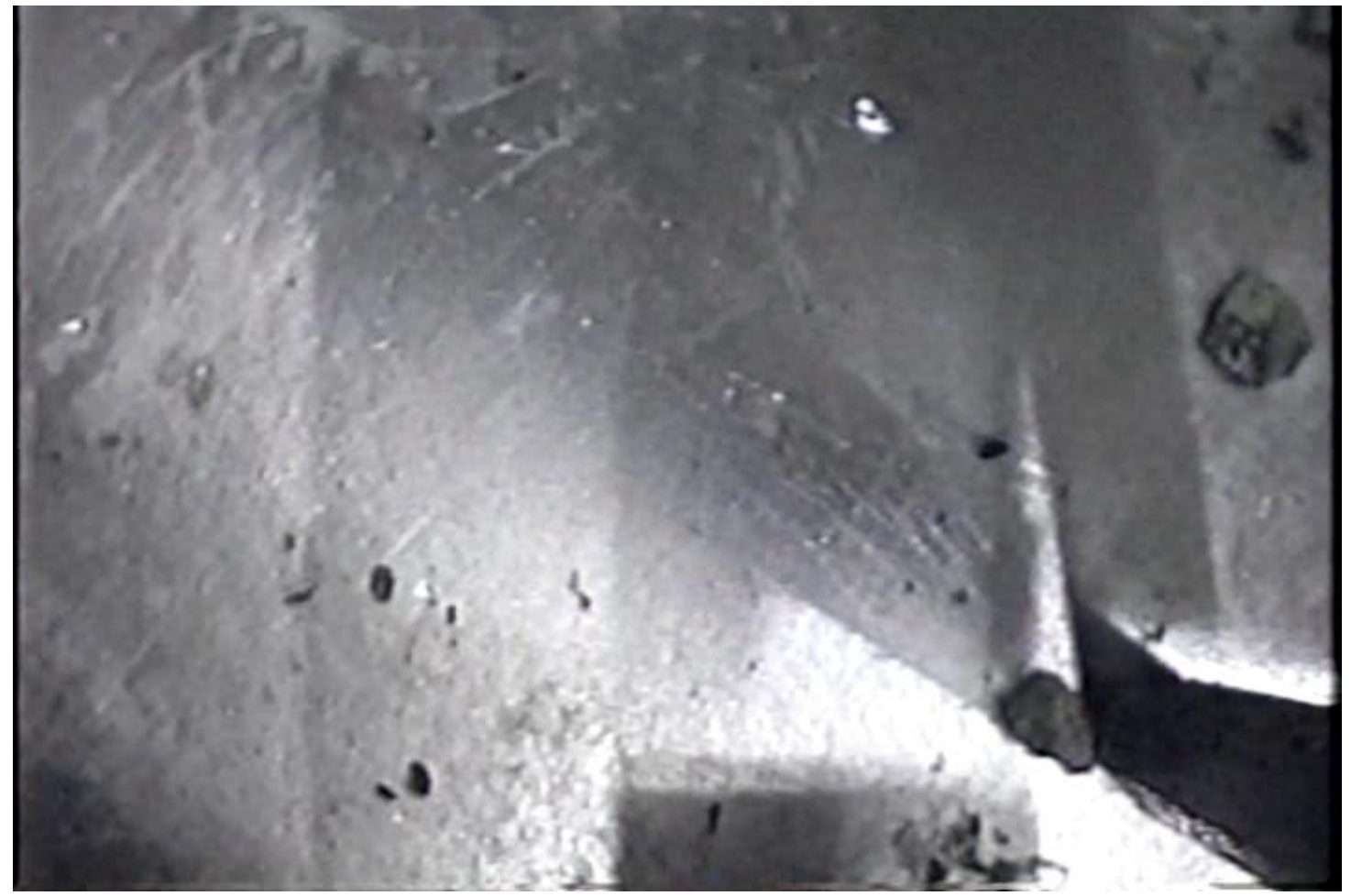

Figure 4.8. Sample 96-13 Shear Strength Estimate 4. Hex wrench in contact with chunk for impingement. 


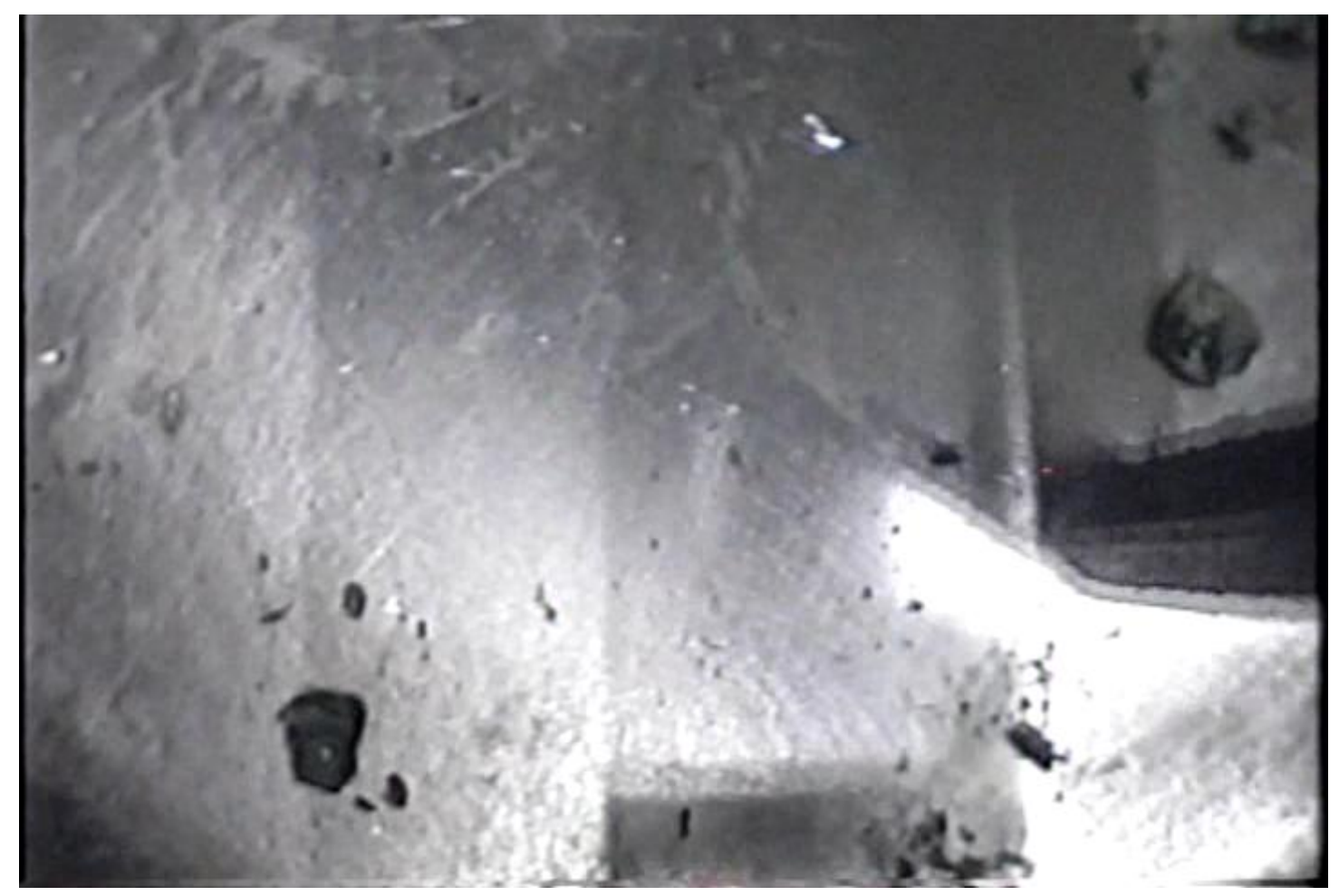

Figure 4.9. Sample 96-13 Shear Strength Estimate 4. Chunk expelled to lower left, "chip" is left in original location.

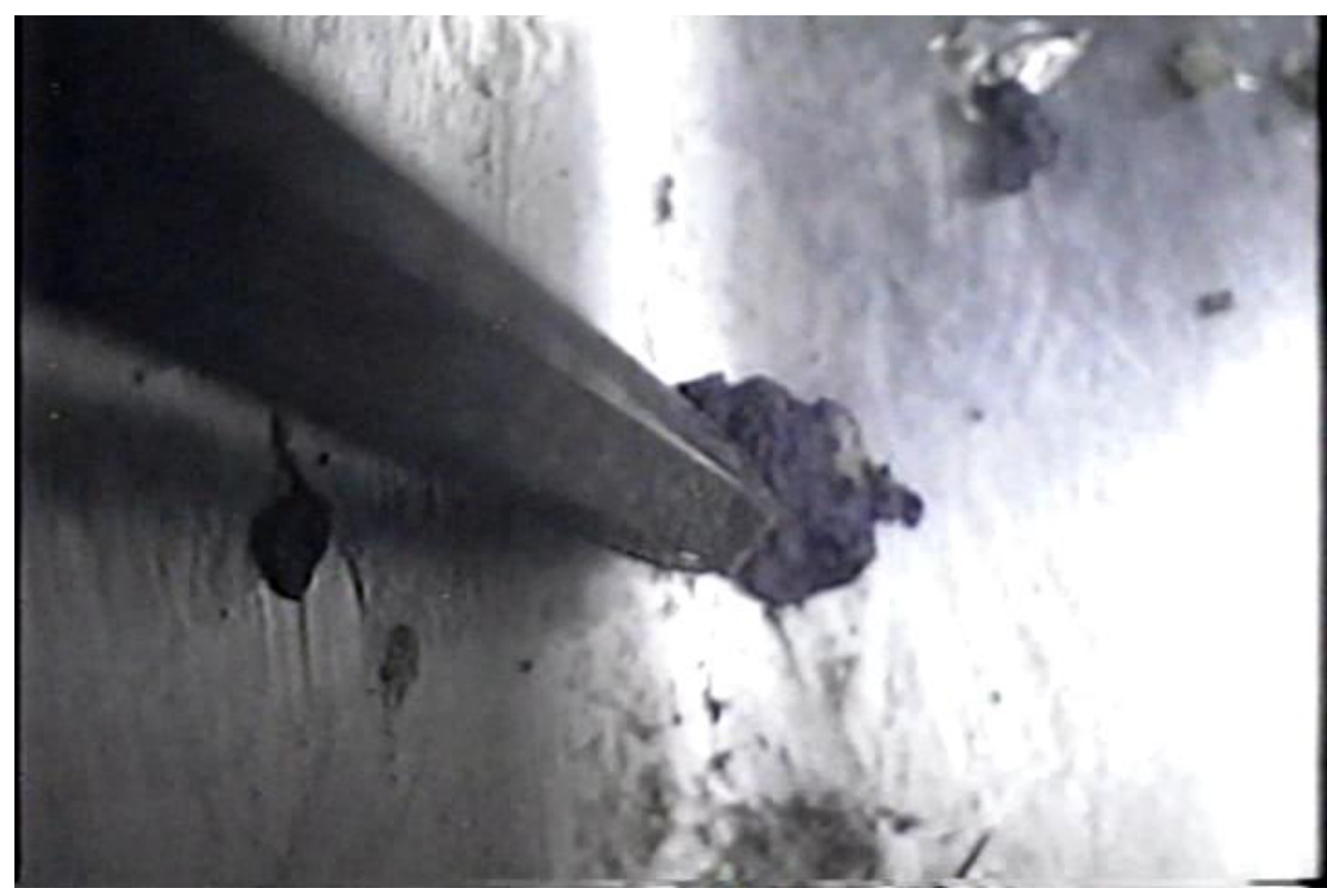

Figure 4.10. Sample 96-13 Shear Strength Estimate 5. Hex wrench placement. 


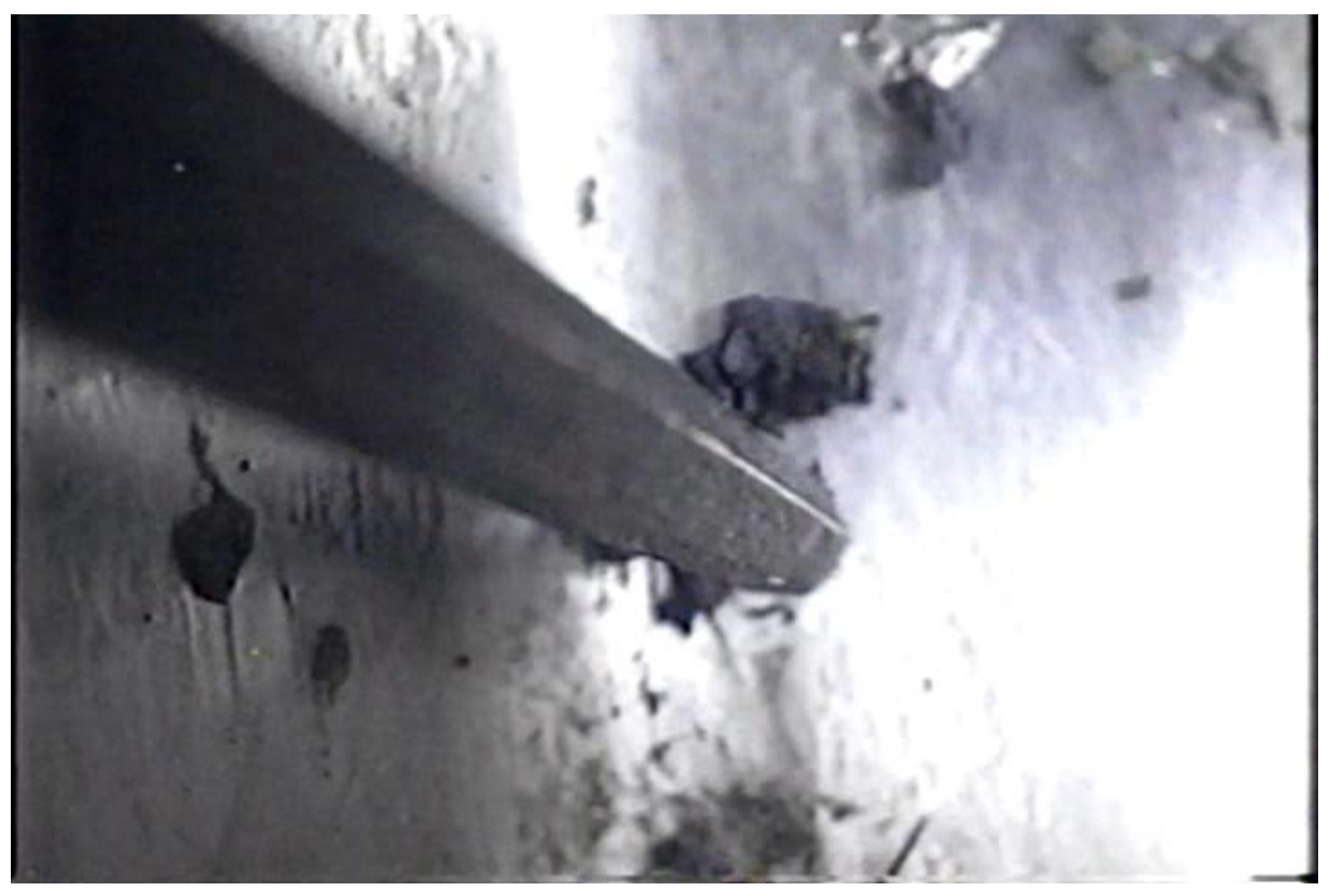

Figure 4.11. Sample 96-13 Shear Strength Estimate 5. After fracture.

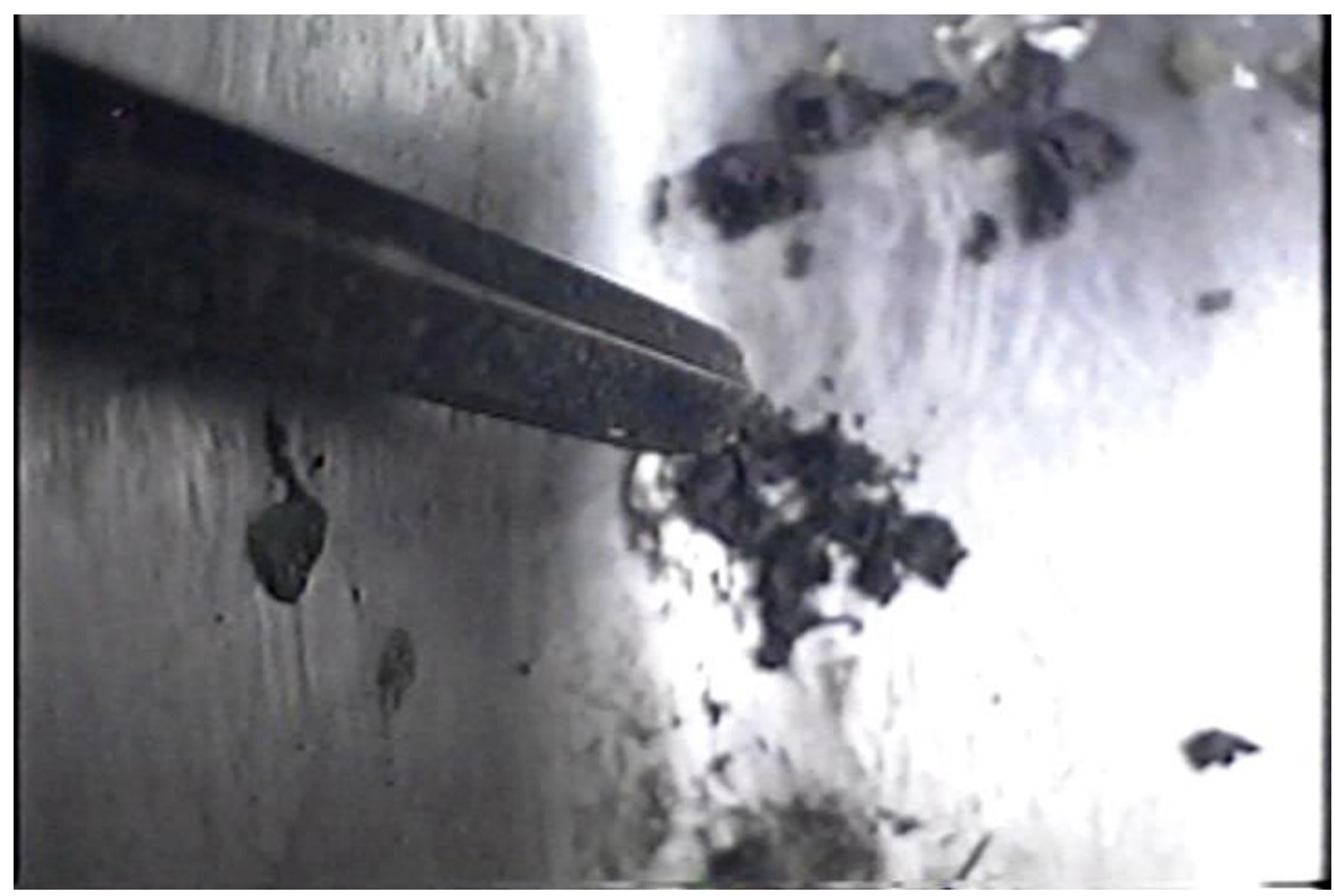

Figure 4.12. Sample 96-13 Shear Strength Estimate 6. Initial sample condition prior to hex wrench placement. 


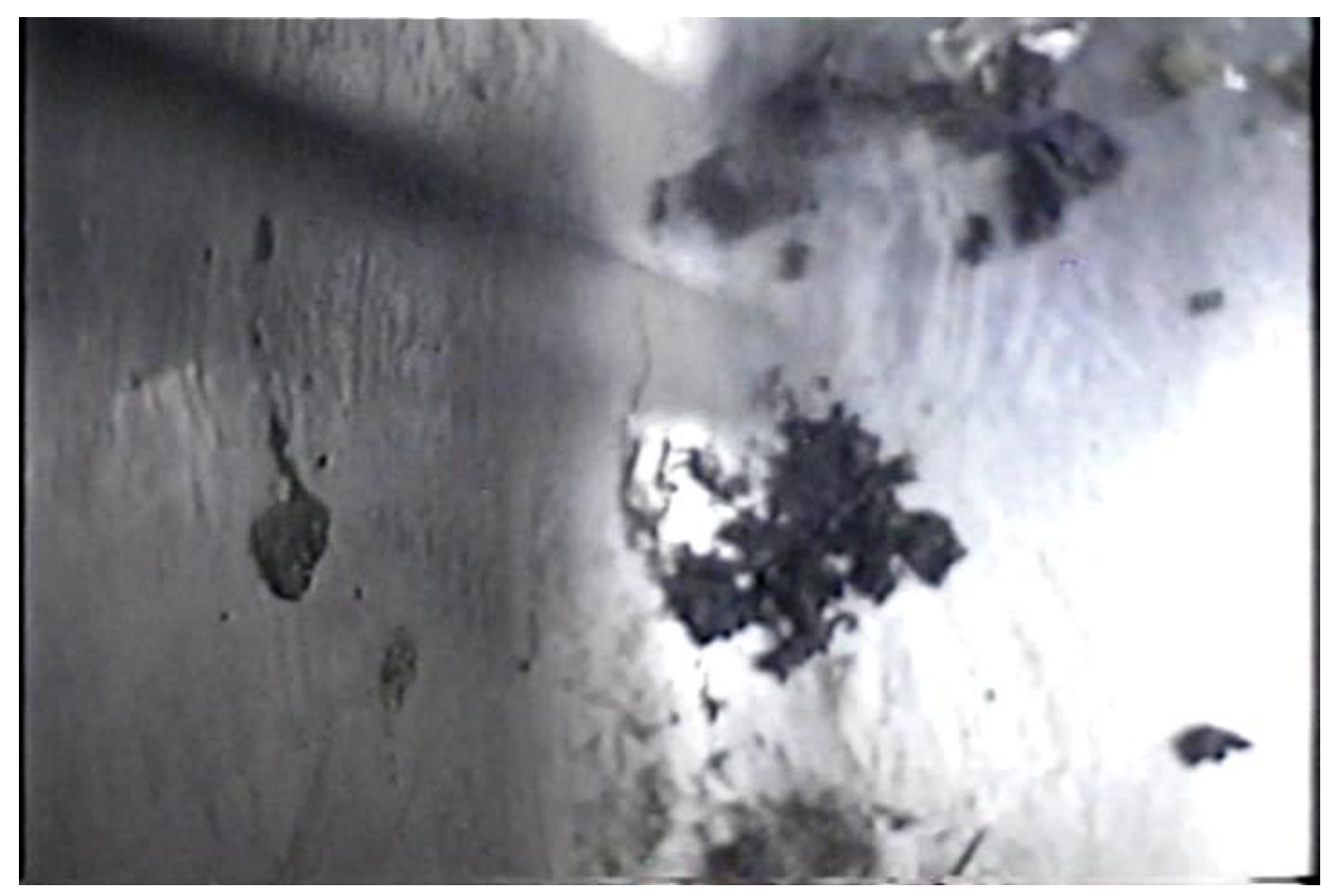

Figure 4.13. Sample 96-13 Shear Strength Estimate 6. Post hex wrench interaction.

The methodology for estimating shear strength via the impingement of an object into a material presented in Gauglitz et al. (2009) may perhaps be most meaningfully applied to estimate numbers 1 through 3 given the nature of the action. However, the shear strength methodology from Gauglitz et al. (2009) requires the load at which the impingement first occurs. Thus, as impingement occurred at the lowest applied load for estimate numbers 1 through 3, the shear strength for these estimates may be an upper bound. That is, the impingement may have been possible at a lesser applied load. As indicated in Table 4.1, estimates 1, 5, and 6 are applicable to the bulk material, estimates 2 and 3 are for the paste, and estimate 4 is for a chunk.

The shear strength is written in Appendix B of Gauglitz et al. (2009) as

$$
\tau_{S}=\frac{F}{\eta A}
$$

where $\mathrm{F}$ is the force required to impinge an object into the material (compressive force), and $\mathrm{A}$ is the object's area (or projected area). Depending on the analysis approach and/or the material considered, the factor relating the impinging pressure and the materials shear strength, $\eta$ ranges from 10 to 100, with typical values for material like Hanford sediment at $\eta \sim 10$. Actual Hanford sediment data suggests $\eta \sim$ 20. Higher $\eta$ values are applicable to slurries with non-settling solids (55 for latex suspension, Buscal et al. 1987, 100 for silica suspension, Buscal et al. 1988).

Equation (4.1) with $\eta$ equal to 10 and 20 is applied to the data of Table 4.1. The estimated shear strength of the bulk material ranges from 15 to $65 \mathrm{kPa}$, the paste 3 to $5 \mathrm{kPa}$, and the chunks 380 to 770 $\mathrm{kPa}$, Table 4.2. These shear strength estimates are based on estimated applied forces, approximated 
contact areas, and the application of an estimate of the relation of compressive and shear stresses and must therefore be treated as qualitative at best.

Although the measurements are qualitative, the increase in shear strength of the bulk material over the paste alone is not unreasonable given the higher strength of the chunks, but also possibly the broader size distribution of the constituents (Zhou et al. 1999; Ancey and Jorrot 2001). Alternatively, Naeini and Baziar (2003) found that the strength of a soil passes through a minimum as the ratio of fine to coarse constituents increased, and so, depending on the initial condition, the broadening of the size distribution may not always necessarily increase a material's strength.

Table 4.2. 96-13 Sample Shear Strength Estimates

\begin{tabular}{ccccc}
\hline & & & \multicolumn{2}{c}{$\begin{array}{c}\text { Estimated Shear Strength } \\
\text { Test Tool }\end{array}$} \\
\cline { 3 - 4 } Estimate Number & (see Table 4.1) & Material & $\eta=10$ & $\eta=20$ \\
\hline $1^{1}$ & spoon & bulk & 30 & 15 \\
$2^{1}$ & forceps & paste & 5 & 3 \\
$3^{1}$ & forceps & paste & 5 & 3 \\
4 & hex wrench & chunk & 770 & 380 \\
5 & hex wrench & bulk & 65 & 30 \\
6 & hex wrench & bulk & 65 & 30 \\
1. Shear strength estimate may be an upper bound as impingement occurred at the lowest estimated applied load. \\
\hline
\end{tabular}

The sample 96-13 shear strength results of Table 4.2 are high relative to other K-Basin sludge (Gauglitz and Terrones, 2002). However, Delegard et al. (2007) provide penetrometer-based shear strengths for five hydrothermally tested K-Basin samples that are similar to the 96-13 results. Qualitative comparison by the principle investigators and hot-cell operators of the 96-13 sample (Delegard et al. 2005) and the hydrothermally tested samples (Delegard et al. 2007) suggests that the 96-13 sample had a lower shear strength than Test 1, $170 \mathrm{kPa}$, and was stronger than Tests and 2, 3, 4, and 5 at 120,16, 9, and $13 \mathrm{kPa}$, respectively (shear strengths for Tests 1, 2, 3, and 4 of Delegard et al. (2005) provided in Table 4.3). The qualitative bulk sample 96-13 shear strength estimates of Table 4.2, 15 to $65 \mathrm{kPa}$, may thus be low.

The qualitative consistency descriptions provided in Delegard et al. (2007) are also enlightening. Depending on the consistency descriptions used, Tests 1 and 2 may be described as "stiff" or "very stiff," indicating that they "can be indented slightly by thumb" or "readily indented by thumbnail," respectively. Similarly, Tests 3 through 5 may be described as "very soft," indicating that they are "easily penetrated 1 inch by thumb." The visual observations of sample 96-13 indicate that it could be described as "stiff."

\subsection{K-Basin Sample Erosion}

Erosion tests were performed on the hydrothermal test samples of Delegard et al. (2007). As discussed in Section 4.1, the estimated shear strength of sample 96-13 is estimated to be between Tests 1 and Tests 2 or Tests 2 and 4 of Delegard et al. (2007), so it is reasonable to expect that the erosion behavior of sample 96-13 may be bounded by these samples. The erosion test results for the hydrothermal test samples are thus investigated. 
Comparison of the applied shear stress to the measured shear strength can be made to investigate critical shear stress for these erosion tests (see Sections 2.2.1.3 and 2.2.1.4, see also proposed testing method described in Section 3.2.1). The volumetric flow from the agitator can be estimated by

$$
Q=N_{Q} N D^{3}
$$

where $\mathrm{N}$ is the impeller rotational speed, and $\mathrm{D}$ is the impeller diameter (Paul et al. 2004). The pumping number $\mathrm{N}_{\mathrm{Q}}$ depends on the impeller type, impeller diameter to vessel diameter ratio $(\mathrm{D} / \mathrm{T})$, and impeller Reynolds number given by

$$
\operatorname{Re}_{j}=\frac{\rho_{l} N D^{2}}{\mu_{l}}
$$

For a D/T less than $0.55, \mathrm{~N}_{\mathrm{Q}}=0.79$ for a pitched blade turbine (Paul et al. 2004). Above a D/T of 0.55 , pitched blade turbines transition to radial flow impellers. Thus, with the employed $\mathrm{D} / \mathrm{T}$ of 0.71 , estimating an axial $\mathrm{Q}$ from Equation (4.2) for the erosion tests with $\mathrm{N}_{\mathrm{Q}}=0.79$ may be expected to result in an overestimate of the actual axial flow. However, the sludge samples were located at the periphery of the beaker at or beyond the impeller tips and would have thus been subjected to radial flow regardless. Approximations using continuity to estimate the axial and radial flow in the beaker around the impeller can be made, but the area of the blade circumference and separation from the beaker bottom is essentially equivalent to the area of the impeller. Thus, the assumptions required to assign radial and axial flow in conjunction with the actual sample location are not made, and $\mathrm{N}_{\mathrm{Q}}=0.79$ is used for the purposes of this qualitative investigation. The area of the flow is conservatively taken as the blade circumference and separation from the beaker bottom (average velocity is maximized, flow is axial [as indicated by $\mathrm{N}_{\mathrm{Q}}=0.79$ ] and out at the samples).

The applied stress from the agitator-induced flow is computed as

$$
\tau=\frac{1}{2} \rho_{l} \frac{Q}{A}
$$

where the liquid density is assumed to be $1 \mathrm{~g} / \mathrm{mL}$, Q is the volumetric flow from Equation (4.2), and A is the flow area assumed above (blade circumference and separation from the beaker bottom $\sim 0.003 \mathrm{~m}^{2}$ ).

The percent $\tau / \tau_{\mathbf{s}}$ is provided in Table 4.4. The critical shear for both surface and mass erosion is indicated to be much less than $1 \%$ of the material's shear strength, which is significantly less than expected; see Section 2. It is thus possible that the observed erosion was due to impacts of the sample pieces with the impeller or the beaker wall rather than liquid erosion. This postulation is further investigated by considering that the maximum possible flow velocity generated by the agitator would be equivalent to the impeller tip speed. The velocity Q/A in Equation (4.4) is replaced the tip speed. Again, the percent $\tau / \tau_{\mathbf{S}}$ is much less than $1 \%$, Table 4.4 .

An additional plausible explanation for the unusually low $\tau / \tau_{\mathbf{S}}$ is material heterogeneity. Heterogeneity may result in anomalous shear strength measurements. The UCS measurements of Delegard et al. (2007) match well with the UCS ranges for the identified qualitative consistency 
descriptions. It is thus reasonable to expect that the penetrometer shear strengths, noting the potential uncertainty relation of penetrometer UCS to shear strength for K-Basin materials (Section 3), are not influenced by the material's potential heterogeneity.

Heterogeneity of the sample may also influence the erodibility of the material (Sections 2.2.1.4 and 2.2.3.3). "Weak" material relative to the shear strength of the bulk material (i.e., the "paste" of sample 96-13) may be eroded at lower applied stress, thereby failing the bulk material. It is uncertain if this phenomena occurred for the samples of Delegard et al. (2007).

This analysis of the available K-Basin sludge erosion data demonstrates that the actual mechanism of erosion is uncertain. Either the hydrothermally treated sludge was much easier to erode than expected based on the material's shear strength, or the material was broken-up by mechanical means due to impacts of the sample pieces with the impeller or the beaker wall. For the former case, it may be indicated that the K-Basin sludge shear strength provides an extremely high estimate for the required applied stress for erosion. This possible indication must be evaluated experimentally. The analysis also demonstrates that quantification of erosion is difficult in heterogeneous materials with strength characteristics similar to sample 96-13.

Table 4.4. Processed K-Basin Sludge Erosion Applied Shear Comparison

\begin{tabular}{|c|c|c|c|c|c|c|}
\hline \multirow[b]{2}{*}{ Test } & \multirow{2}{*}{$\begin{array}{c}\text { Shear } \\
\text { Strength } \\
(\mathrm{kPa})\end{array}$} & \multirow[b]{2}{*}{$\begin{array}{l}\text { Agitation } \\
\text { Test Count }\end{array}$} & \multirow[b]{2}{*}{$\begin{array}{c}\text { Agitation Conditions } \\
\text { Evaluated }\end{array}$} & & \multicolumn{2}{|c|}{$\tau / \tau_{\mathbf{S}}(\boldsymbol{\%})$} \\
\hline & & & & Erosion State & $\begin{array}{l}\text { Volumetric } \\
\text { Flow }\end{array}$ & Tip Speed \\
\hline \multirow{2}{*}{ Test 1} & \multirow{2}{*}{170} & 2 & $100 \mathrm{rpm}, 5 \mathrm{~min}$ & surface erosion & 0.003 & 0.029 \\
\hline & & 3 & $300 \mathrm{rpm}, 5.5 \mathrm{~min}$ & surface erosion & 0.024 & 0.261 \\
\hline \multirow{2}{*}{ Test 2} & \multirow{2}{*}{120} & 7 & $100 \mathrm{rpm}, 5 \mathrm{~min}$ & surface erosion & 0.004 & 0.041 \\
\hline & & 8 & $300 \mathrm{rpm}, 5 \mathrm{~min}$ & surface erosion & 0.033 & 0.370 \\
\hline Test 4 & 9 & 10 & $40 \mathrm{rpm}, 5 \mathrm{~min}$ & mass erosion & 0.008 & 0.088 \\
\hline Test 5 & 13 & 15 & $100 \mathrm{rpm}, 8 \mathrm{~min}$ & mass erosion & 0.034 & 0.380 \\
\hline
\end{tabular}

It should be noted however, the estimated range of shear strengths for Sample 96-13 and the hydrothermal test samples of Delegard et al. (2007) are not beyond the range applicable to erosion studies of cohesive materials. While most erosion studies dealing with cohesive materials (mainly clay soils) work with materials that have $\tau_{\mathrm{S}}<50 \mathrm{kPa}$, studies have been done for materials with $\tau_{\mathrm{S}}$ in the range of 100 to $400 \mathrm{kPa}$ (Freeman 1970). 



\subsection{Conclusions}

Packaged K-Basin sludge will be transported to T Plant on the Hanford Site where it will be interim stored. The sludge will be retrieved from the storage containers and processed for disposal. A sample of canister sludge sample with a high uranium content, designated 96-13, "self-cemented" during laboratory storage. This sample was uncharacteristically strong compared to expected K-Basin material. The purpose for this work is to evaluate the potential retrieval of such sludge after storage at the T Plant via jet erosion.

This report identifies the modes of erosion and the methods used to measure/assess the erodibility of sludge and determines those parameters applicable to jet erosion. The erodibility parameters of sample 96-13 are characterized to the extent possible. This work was completed via literature review, past experience at Pacific Northwest National Laboratory, and observation of sample 96-13 video.

Sample 96-13 is characterized as a heterogeneous cohesive sediment with "paste" material (estimated shear strength 3 to $5 \mathrm{kPa}$ ) joining "chunks" (estimated shear strength 380 to $770 \mathrm{kPa}$ ) The bulk material shear strength is estimated at 15 to $65 \mathrm{kPa}$, which is within the range of shear strengths for cohesive sludges used for erosion investigations. These shear strength estimates are taken from visual observation of the 96-13 sample settling study disassembly video and are based on estimated applied forces, approximated contact areas, and the application of an estimate of the relation of compressive and shear stresses and must therefore be treated as qualitative. The estimated shear strength results are qualitatively in agreement with the measured shear strength for hydrothermally treated K-Basin samples.

Evaluation of the erosion of four of these hydrothermally treated K-Basin samples was conducted based on previous experimental work. The actual mechanisms for the disassociation of the material is in question based on the assessment. The analysis also demonstrates that quantification of erosion is difficult in heterogeneous materials with strength characteristics similar to sample 96-13.

A shear strength measurement technique using a pocket penetrometer has been applied in a previous study to K-Basin samples with similar shear strengths to that estimated for sample 96-13. It is recommended that this technique is fully vetted with homogenous K-Basin-like materials by direct comparison to shear vane results. Heterogeneity may result in anomalous shear strength measurements and must thus be investigated. Changes in the composition or size distribution of the non-cohesive particulate may result in large variations in shear strength measurements with negligible change in the erosive resistance of the bulk material. Sensitivity in the bulk erodibility to changes in the heterogeneous makeup of the material should be evaluated to aid in defining bounding conditions for system performance.

A summary of the literature on erosion phenomena for and application to both impinging and parallel wall jets for cohesive and non-cohesive materials is presented. Erosion will occur if the measured shear strength of the material is applied. Erosion may occur at an applied shear stress less than the measured shear strength of the material. The shear stress corresponding to the onset of erosion is termed the critical shear stress. Direct measurements of this critical shear stress are somewhat subjective and material dependent. 
The critical shear stress for a given material can be predicted from in situ or laboratory erosion measurements. There are different measurement techniques that may be used, but all require multiple data points such that the critical shear stress at zero-erosion (corresponding to the predicted onset of erosion) can be identified. Some of these erosion measurement techniques allow the erosion rate to be determined. For a shear stress beyond the critical shear stress applied to a material, two states of erosion will dominate, surface and bulk erosion. While bulk erosion may be initiated at applied shear stresses below a material's measured shear strength, it will occur if the applied stress is equal to or exceeds the measured shear strength.

Methods for determining the critical shear stress for the onset bulk erosion over a range of cohesive materials have not been successfully developed outside of experimental mapping of the erosion process as a function of applied shear stress for the specific material of interest. It is recommended that these same techniques be considered for application with hot-cell samples by applying a changed geometry in which the applied shear stress is quantifiable. However, scaling issues must be addressed if small (relative to past work) scale tests are to be performed.

The erosion rate will increase linearly with increases in the applied shear stresses in excess of the critical shear stress until the onset of bulk erosion. Bulk erosion will always be greater than surface erosion. Erosion of heterogeneous cohesive materials may be confounded if erosion results in the creation of an erosion-resistive layer of non-cohesive material. That is, erosion can remove the "binding" material and leave behind larger particulate that is non-cohesive. This residual non-cohesive material has the potential to bury the remaining heterogeneous material under a material layer with an erosive resistance greater than the capacity of the erosion source. Characterization of the non-cohesive portion allows for the analytical assessment of the erodibility of the material.

The follow-on studies recommended above include:

- A direct comparison be made of pocket-penetrometer and shear vane results for homogenous KBasin-like materials.

- Comparison be made for pocket-penetrometer and shear vane results for heterogeneous materials.

- Critical shear stress measurement techniques be considered for application with hot-cell samples by applying a known flow field to a specific geometry in which the applied shear stress is quantifiable.

- The erodibility of the non-cohesive portion of the K-Basin sludge be assessed to confirm a bounding condition for material retrieval.

- The erosion rate of both the bulk material and the non-cohesive material be assessed.

These recommendations for follow-on work are intended to allow the project to determine:

- The bounding conditions that may exist for the initiation of erosion.

- The system performance requirements needed to conduct feasible retrieval operations (duration and fluid requirements).

- The potential risk associated with creating more challenging retrieval condition as a result of process operations. 


\subsection{References}

Ade F and N Rajaratnam. 1998. "Generalized Studies of Erosion by Circular Horizontal Turbulent Jets." Journal of Hydraulic Research, IAHR, 36(4):613-635.

Aderibigbe OO and N Rajaratnam. 1996. "Erosion of Loose Beds by Submerged Circular Impinging Jets Vertical Turbulent Jets.” Journal of Hydraulic Research, IAHR, 34(1):19-33.

Amos CL, TF Sutherlund, D Cloutier, and S Patterson. 1999. "Corrasion of a Remoulded Cohesive Bed by Saltating Littorinid Shells.” Continental Shelf Research 20(10-11):1291-1315.

Ancey C and H Jorrot. 2001. "Yield Stress for Particulate Suspensions within a Clay Dispersion." Journal of Rheology 45(2):297-319.

Bamberger JA, PA Meyer, JR Bontha, CW Enderlin, DA Wilson, AP Poloski, JA Fort, ST Yokuda, HD Smith, F Nigl, MA Friedrich, DE Kurath, GL Smith, JM Bates, and MA Gerber. 2005. "Technical Basis for Testing Called Pulse jet Mixing Systems for Non-Newtonian Slurries.” PNWD-3551, BattellePacific Northwest Division, WTP-RPT-113, Waste Treatment Project, Richland, Washington.

Barnes HA. 1999. “The Yield Stress - A Review or ' $\pi \alpha \nu \tau \alpha \rho \varepsilon \imath '$ - Everything Flows?” Journal of NonNewtonian Fluid Mechanics 81:133-178.

Beltaos S and N Rajaratnam. 1974. "Impinging Circular Turbulent Jets.” Journal of the Hydraulics Division, ASCE, 100(HY10):1313-1328.

Beltaos S and N Rajaratnam. 1977. "Impingement of Axisysmetric Developing Jets.” Journal of Hydraulic Research, IAHR, 15(4):311-327.

Billam J. 1977. "Correlations Between Cone Resistance and Vane Shear Strength in some Scandinavian Soft to Medium Stiff Clays: Discussion.” Canadian Geotechnical Journal 14:272.

Blevins RD. 1992. Applied Fluid Dynamics Handbook. Krieger Publishing Co., Malabar, Florida.

Burns CA, RC Daniel, CW Enderlin, M Luna, and AJ Schmidt. 2009. Shear Strength Measurement Benchmarking Tests for K Basin Sludge Simulants. PNNL-18479, Pacific Northwest National Laboratory, Richland, Washington.

Buscall R, PDA Mills, JW Goodwin, and DW Larson. 1988. Scaling Behaviour of the Rheology of Aggregate Networks Formed from Coloidal Particles. Journal of the Chemical Society, Faraday Transactions 1, 84 (12): 4249-4260.

Buscall R, IJ McGowan, PDA Mills, RF Stewart, D Sutton, LR White, and GE Yates. 1987. The Rheology of Strongly-Flocculated Suspensions. Journal of Non-Newtonian Fluid Mechanics, 24: 183-202. 
Chhabra RP. 1992. Bubbles, Drops, and Particles in Non-Newtonian Fluids. CRC Press, Inc., Boca Raton, Florida.

Delegard CH, AJ Schmidt, and BM Thornton. 2007. Hydrothermal Testing of K Basin Sludge and N Reactor Fuel at Sludge Treatment Project Operating Conditions. PNNL-16496, Pacific Northwest National Laboratory, Richland, Washington.

Delegard CH, AP Poloski, AJ Schmidt, and JW Chenault. 2005. Characterization of Compaction and Dryout Properties of KE Basin Sludge During Long-Term Storage. PNNL-15092, Pacific Northwest National Laboratory, Richland, Washington.

Fredlund DG and SK Vanapalli. 2002. Shear Strength of Unsaturated Soils. Chapter 2.7, Handbook of Agronomy, Soil Society of America.

Freeman, WS. 1970. "Shear Strength of Winnipeg Clays." PhD thesis, University of Glasgow, Glasgow, Scotland.

Garde, RJ and KG Ranga Raju. 2000. Mechanics of Sediment Transportation and Alluvial Stream Problems. Sandeep Press, Daryaganj, New Delhi.

Gauglitz PA, BE Wells, JA Fort, and PA Meyer. 2009. An Approach to Understanding Cohesive Slurry Settling, Mobilization, and Hydrogen Gas Retention in Pulsed Jet Mixed Vessels. PNNL-17707, Pacific Northwest National Laboratory, WTP-RPT-177, Rev. 0, Waste Treatment Project, Richland, Washington.

Gauglitz PA, and G Terrones. 2002. Estimated Maximum Gas Retention form Uniformly Dispersed Bubbles in K Basin Sludge Stored in Large-Diameter Containers. PNNL-13893, Pacific Northwest National Laboratory, Richland, Washington.

Gauglitz PA and JT Aikin. 1997. Waste Behavior During Horizontal Extrusion: Effect of Waste Strength for Bentonite and Kaolin/Ludox Simulants and Strength Estimates for Wastes from Hanford Waste Tanks 241-SY-103, AW-101, AN-103, and S-102. PNNL-11706, Pacific Northwest National Laboratory, Richland, Washington.

Gessler J. 1971. "Beginning and Ceasing of Sediment Motion." Chap. 7. River Mechanics, H.W. Shen (ed.). Water Resources Publications. Littleton, Colorado.

Hobson PM. 2008. "Rheologic and Flume Erosion Characteristics of Georgia Sediments from Bridge Foundations." School of Civil and Environmental Engineering, Georgia Institute of Technology. Atlanta, Georgia.

Holtz RD and WD Kovacs. 1981. An Introduction to Geotechnical Engineering. Prentice-Hall, Inc., Englewood Cliffs, New Jersey.

Julien PY. 1995. Erosion and Sedimentation. Cambridge University Press, New York. 
Kramer H. 1935. "Sand Mixtures and Sand Movement in Fluvial Models." Transactions of the American Society of Chemical Engineers 100:798-878.

Mazurek KA and T Hossain. 2007. "Scour by Jets in Cohesionless and Cohesive Soils." Canadian Journal of Civil Engineering 34:744-751.

Mazurek KA. 2001. "Scour of Clay by Jets." Ph.D. thesis, Department of Civil and Environmental Engineering, University of Alberta, Edmonton, Alberta, Canada.

Mazurek KA, Y Liu, and N Rajaratnam. 2002. "Scour of Cohesive Material by Circular Wall Jets." In: "Proceedings of the 16th Hydrotechnical Conference of the CSCE." Burlington, Ontario, CD-ROM. Canadian Society for Civil Engineering. Montreal, Quebec, Pp 1-12.

Mehta AJ. 1991. "Review notes on Cohesive Sediment Erosion.” In: Coastal Sediments, Vol 1, NC Kraus, KJ Gingerich, and DL Kriebel, editors, American Society of Civil Engineers.

Naeini SA and MH Baziar. 2003. "Effect of Fines on Steady-State Strength of Mixed and Layered Samples of Sand.” Solid Dynamics and Earthquake Engineering 24 (2004):181-187.

Nquyen QD and DV Boger. 1992. "Measuring the Flow Properties of Yield Stress Fluids." Annual Review of Fluid Mechanics 24:47-88.

Nquyen QD and DV Boger. 1983. "Yield Stress Measurement for Concentrated Suspensions.” Journal of Rheology 27(4):321-349.

Onishi Y, BE Wells, ST Yokuda, and GT Terrones. 2003. Feasibility Study on Using a Single Mixer Pump for Tank 241-AN-101 Waste Retrieval. PNNL-14105. Pacific Northwest National Laboratory, Richland, Washington.

Paul EL, VA Atiemo-Obeng, and SM Kresta. 2004. Handbook of Industrial Mixing. John Wiley and Sons, Inc., Hoboken, New Jersey.

Poloski AP, PR Bredt, RC Daniel, and AE Saez. 2006. "The Contribution of Frictional Contacts to the Shear Strength of Coarse Glass Bead Powders and Slurries.” Rheologica Acta 46:249-259.

Rajaratnam N. 1976. Turbulent Jets. Elsevier Scientific Publishing Co., Amsterdam - Oxford -New York.

Rajaratnam N. 1982. "Erosion by Submerged Circular Jets." Journal of the Hydraulics Division, ASCE 108(HY2):262-267.

Rajaratnam N and B Berry. 1977. "Erosion by Circular Turbulent Wall Jets." Journal of Hydraulic Research. IAHR 15(4):277-289.

Rajaratnam N, and BS Pani. 1974. "Three Dimensional Turbulent Wall Jets." Journal of the Hydraulics Division, ASCE 100(HYI):69-83. 
Rassat SD, LA Mahoney, BE Wells, DP Mendoza, and DD Caldwell. 2003. Assessment of Physical Properties of Transuranic Waste in Hanford Single-Shell Tanks. PNNL-14221, Pacific Northwest National Laboratory, Richland, Washington.

Schmidt AJ, CH Delegard, SA Bryan, MR Elmore, RL Sell, KL Silvers, SR Gano, and BM Thornton. 2003. Gas Generation from K East Basin Sludges and Irradiated Metallic Uranium Fuel Particles Series III Testing. PNNL-14346, Pacific Northwest National Laboratory, Richland, Washington.

Simons BD and F Sentürk. 1992. Sediment Transport Technology Water and Sediment Dynamics. Water Resource Publications, Littleton, Colorado.

Stewart CW, JM Alzheimer, ME Brewster, G Chen, RE Mendoza, HC Reid, CL Shepard, and G Terrones. 1996. In Situ Rheology and Gas Volume in Hanford Double-Shell Waste Tanks. PNL-11296, Pacific Northwest National Laboratory, Richland, Washington.

Tanaka H. 2002. A Comparative Study on Geotechnical Characteristics of Marine Soil Deposits Worldwide. In: Proceedings of the Twelfth International Offshore and Polar Engineering Conference, Kitakyushu, Japan, May 26-31, 2002.

Tanaka H. 1994. "Vane Shear Strength of a Japanese Marine Clay and Applicability of Bjerrum's Correction Factor." Soils and Foundations 34 (3):39-48.

Task committee on Preparation of Sedimentation Manual. 1966. "Sediment Transportation Mechanics; Initiation of Motion.” Journal of the Hydraulics Division, ASCE, 92(HY2):291-314.

Tingey JM, J Gao, CH Delegard, LM Bagaason, and BE Wells. 2003. Physical Property and Rheological Testing of Actual Transuranic Waste from Hanford Single-Shell Tanks. PNNL-14365, Pacific Northwest National Laboratory, Richland, Washington.

Tolhurst TJ, KS Black, SA Shayler, S Mather, I Black, K Baker, and DM Paterson. 1999. "Measuring the in situ Erosion Shear Strength of Intertidal Sediments with Cohesive Strength Meter (CMS)." Estuarine, Coastal, and Shelf Science 49(2):281-294.

Tsuchida T. 2000. "Evaluation of Undrained Shear Strength of Soft Clay with Consideration of Sample Quality." Soils and Foundations 40(3):29-42.

Van Olphen H. 1977. An Introduction to Clay Colloid Chemistry. John Wiley \& Sons, New York.

Winterwerp JC and WGM Van Kesteren. 2004. "Introduction to the Physics of Cohesive Sediment in the Marine Environment." Developments in Sedimentology, 56. Amsterdam, Netherlands: Elsevier ISBN 0444515534.

Wu S and N Rajaratnam. 1990. "Circular turbulent Wall jets on Rough Boundaries.” Journal of Hydraulic Research, IAHR, 28(5):581-589. 
Zhou Z, MJ Solomon, PJ Scales, and DV Boger. 1999. "The Yield Stress of Concentrated Flocculated Suspensions of Size Distributed Particles.” Journal of Rheology 43(3):1999.

Zhu, Y., J Lu, H Liao, J Wang, B Fan, and S Yao. 2008. "Research on Cohesive Sediment Erosion by Flow: An Overview." Science in China Press. Science in China Series E: Technological Sciences. Vol. 51, No. 11, 2001-2012. 

PNNL-18831

\section{Distribution}

No. of

Copies

OFFSITE
No. of

Copies

ONSITE

8 Pacific Northwest National Laboratory
R. C. Daniel
P7-22
C. H. Delegard
P7-25
C. W. Enderlin
K7-15
P. A. Gauglitz
K9-75
R. A. Peterson
P7-22
A. J. Schmidt
P8-60
B. M. Thornton
P7-07
B. E. Wells
K7-15
Information Release (pdf)

11 CH2M Hill Plateau Remediation Company

R. B. Baker

X5-50

D. W. Hamilton

A3-06

J. O. Honeyman

A3-06

M. E. Johnson

A0-26

C. R. Miska

A3-06

C. A. Petersen

A $0-26$

R. E. Raymond

A $0-26$

W. W. Rutherford

A3-06

M. J. Schliebe

A3-06

N. J. Sullivan

A3-06

STP Project File (N. Fouad)

H6-08

1 Mission Support Alliance

B. J. Makenas

H7-09

Distr. 1 




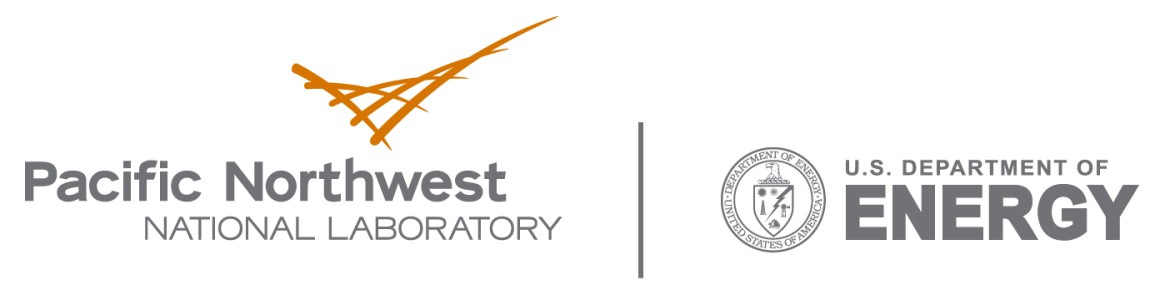

902 Battelle Boulevard

P.O. Box 999

Richland, WA 99352

1-888-375-PNNL (7665)

www.pnl.gov 